\title{
Development and Research Progress of Anti-Drug Resistant Bacteria Drugs
}

\author{
Xiangyi Cui \\ Yuhong Lü ${ }^{1,2}$ \\ Changwu Yue ${ }^{1,2}$ \\ 'Key Laboratory of Microbial Drugs \\ Innovation and Transformation of Yan'an, \\ School of Basic Medicine, Yan'an \\ University, Yan'an, 716000, Shaanxi, \\ People's Republic of China; ${ }^{2}$ Shaanxi \\ Engineering \& Technological Research \\ Center for Conversation \& Utilization of \\ Regional Biological Resources, Yan'an \\ University, Yan'an, 7I6000, Shaanxi, \\ People's Republic of China
}

Correspondence: Yuhong Lü; Changwu Yue

Yan'an University, No. 580 Shengdi Road,

Baota District, Yan'an, 716000, Shaanxi,

People's Republic of China

Tel/Fax +86 9l I-2332-067

Email yuhonglyu@I26.com;

changwuyue@I26.com

\begin{abstract}
Bacterial resistance has become increasingly serious because of the widespread use and abuse of antibiotics. In particular, the emergence of multidrug-resistant bacteria has posed a serious threat to human public health and attracted the attention of the World Health Organization (WHO) and the governments of various countries. Therefore, the establishment of measures against bacterial resistance and the discovery of new antibacterial drugs are increasingly urgent to better contain the emergence of bacterial resistance and provide a reference for the development of new antibacterial drugs. In this review, we discuss some antibiotic drugs that have been approved for clinical use and a partial summary of the meaningful research results of anti-drug resistant bacterial drugs in different fields, including the antibiotic drugs approved by the FDA from 2015 to 2020, the potential drugs against drug-resistant bacteria, the new molecules synthesized by chemical modification, combination therapy, drug repurposing, immunotherapy and other therapies.
\end{abstract}

Keywords: multidrug-resistant bacteria, antimicrobial resistance, novel antibiotics, antibiotics, antibiotic discovery

\section{Introduction}

The golden age of antibiotics was ushered in by the accidental discovery of penicillin in 1929. ${ }^{1}$ About $70 \%$ of the antimicrobials used in human medicine today were obtained during the golden age of antibiotic discovery, and most of which were isolated from Actinomycetes. ${ }^{2}$ As one of the most important medical discoveries in the 20th century, antibiotics have revolutionized medical practice with their ability to treat infections caused by pathogenic microorganisms, which has saved countless lives and made important contributions to the prevention and treatment of human infectious diseases. ${ }^{3}$ However, since the 1970s, the research and development of antimicrobials has focused more on the modification or optimization of known compounds in laboratory conditions; obtaining antibiotics with development value from microbial metabolites by pure culture method has been difficult; and fewer antibiotics can be used in clinical trials. ${ }^{4}$ Data display that 270 antibiotics have been approved by the US Food and Drug Administration (FDA) for clinical use from 1928 to early 1970s. ${ }^{5}$ Although infectious diseases caused by bacteria, viruses, parasites, or fungi are the second leading cause of death in the world, only 27 antibiotics out of the 1090 FDA-approved drugs were commercialized between 2000 and $2020 .{ }^{6}$ While the development of antibiotics is becoming increasingly difficult, the resistance of bacteria to antibiotics is increasing year by year. ${ }^{7}$ 
Seven of the 17 Sustainable Development Goals of the United Nations 2030 Agenda are related to antimicrobial resistance (AMR). Drug-resistant diseases kill at least 700,000 people globally each year, and this figure could rise to 10 million a year by $2050 .{ }^{8}$ Without sustained efforts to curb AMR, some 2.4 million people in high-income countries could die from drug-resistant diseases between 2015 and 2050, and the cumulative global economic losses could amount to about $\$ 100$ trillion a year. ${ }^{9}$ At least 2.8 million people in the US become infected with drug-resistant diseases each year, and more than 35,000 die from these diseases. ${ }^{10}$ Around 33,000 people die in Europe each year from infections with various drug-resistant bacteria, and the burden of these infections is equivalent to that of influenza, tuberculosis, and acquired immunodeficiency syndrome combined. ${ }^{11}$ The severity of AMR is particularly acute in low- and middle-income countries because of inadequate surveillance, limited antimicrobial supplies, and inadequate laboratory capacity. ${ }^{12,13}$

At present, the serious lack of new antibiotics and increased antibiotic resistance coexist. ${ }^{14}$ Only eight of the 51 newly developed antibiotics could be classified as innovative drugs to treat antibiotic resistance, and most of which are modifications of existing drugs. ${ }^{15}$ Most antibiotics in use today are natural or derived from natural antimicrobial drugs. ${ }^{16,17}$ The rapid development of drug resistance may render many promising antibacterial drugs useless. ${ }^{18-20}$ The lack of effective antimicrobial agents has greatly weakened our ability to effectively control infection. Thus, new treatment strategies for infectious diseases are urgently needed. ${ }^{21,22}$

\section{Major Drug-Resistant Bacteria}

Despite various strategies adopted in clinical practice, mortality due to antibiotic-resistant bacteria has remarkably increased worldwide. "ESKAPE" pathogens, namely, Enterococcus faecium, Staphylococcus aureus, Klebsiella pneumoniae, Acinetobacter baumannii, Pseudomonas aeruginosa, and Enterobacter spp., are the most common opportunistic pathogens in nosocomial infection. ${ }^{23}$ The acronym "ESKAPE" is close to ESCAPE and vividly reflects the ability of these microorganisms to "escape" the bacterial killing of antibiotics, as well as their insensitivity to conventional antimicrobial therapy. ${ }^{24}$ According to the bacteria and fungi listed in the Centers for Disease Control and Prevention's 2019 Antibiotic Resistance Threat Report, drug-resistant microbial species are classified into urgent, serious, and concerning threats according to their severity. ${ }^{25}$ The urgent, serious and concerning threats of drug-resistant bacteria are shown in Figure 1.

Methicillin-resistant $S$. aureus (MRSA) has severe multidrug resistance to aminoglycosides, ${ }^{26}$ fluoroquinolones, ${ }^{27}$ tetracycline, ${ }^{28}$ macrolides, and other antimicrobial drugs. ${ }^{29,30}$ Vancomycin-resistant Enterococcus (VRE) was first discovered in a clinical isolate in 1986. Vancomycin-resistant S. aureus (VRSA) isolates, which pose serious threat to healthcare, were discovered in 2002 because of the transmission of vanA resistance genes. VRE-induced nosocomial complicated urinary tract infections (cUTIs) has been reported and can lead to bacteremia (blood infection) and even death. ${ }^{31}$ As Gram-negative bacteria (GNB), Escherichia coli, K. pneumoniae, P. aeruginosa and A. baumannii constitute a special threat because of their double-membrane

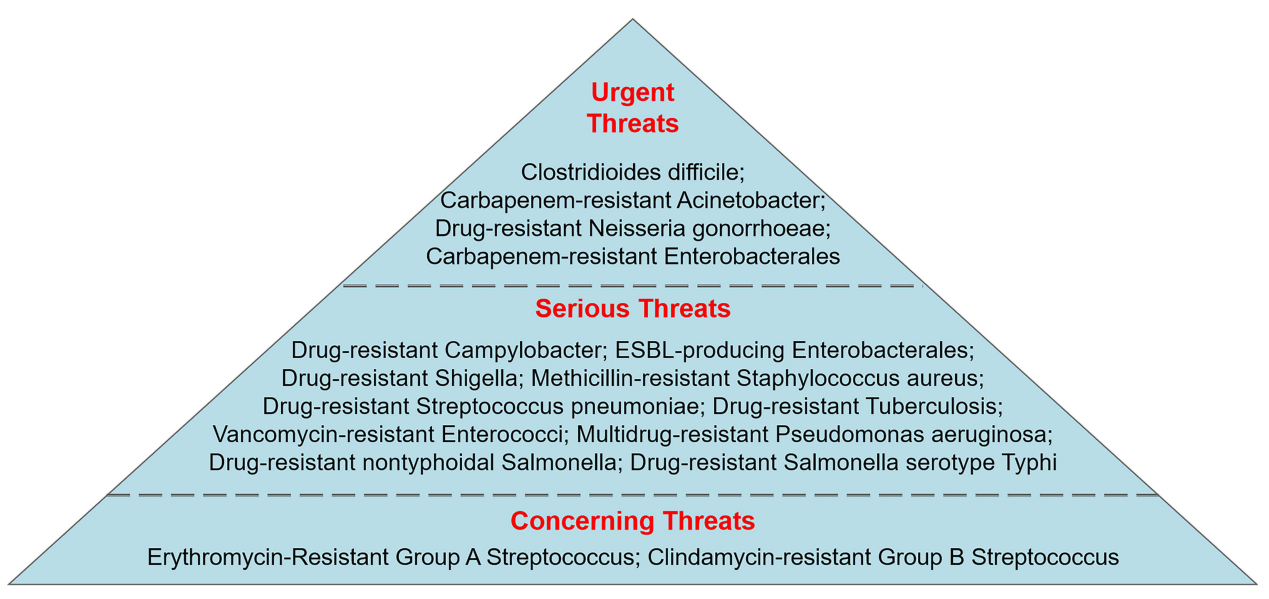

Figure I Centre for Disease prevention and Control (CDC) classification on antibiotic-resistant bacteria that cause public threat.

Notes: Data from: U.S. Department of Health and Human Services; Centers for Disease Control and Prevention. Antibiotic resistance threats in the United States; 2019. Available from: https://www.cdc.gov/drugresistance/pdf/threats-report/2019-ar-threats-report-508.pdf. Accessed March 2, $2021{ }^{205}$ 
coating, which inhibits the access of antibiotics to their target; therefore, the infections caused by these bacteria cannot be cured even by a lethal dose of antibiotics. ${ }^{32}$ Thus, MDR-GNB occupies an important position in nosocomial infections. ${ }^{33,34}$ MDR $A$. baumannii and $P$. aeruginosa are the leading causes of nosocomial infections worldwide and are currently the key priority pathogens of the WHO in terms of drug resistance, AMR surveillance, and the discovery of new antibiotics. ${ }^{35}$ The current resistance rates of Enterobacterales to thirdgeneration cephalosporins are above $10 \%$, and the resistance rates of Enterobactales, $K$. pneumoniae, $P$. aeruginosa, and intensity care unit-acquired A. baumannii to carbapenems are $2 \%-7 \%,>25 \%, 20 \%$ $40 \%$, and $40 \%-70 \%$, respectively. ${ }^{36}$ In addition, linezolid was sold in 2000, and reports of resistance to linezolid appeared in just 1 year. $^{37}$ Therefore, the research and development of new antibiotic drugs that can effectively deal with the infection of these resistant bacteria are urgently needed.

\section{Progress in Research and Development of Drugs Against Drug-Resistant Bacteria Antibiotic Drugs Approved for Marketing by FDA from 2015 to 2021}

The following antibacterial drugs were approved for marketing by FDA from 2015 to 2020. Ceftazidime/avibactam was approved in 2015. Obiltoxaximab and bezlotoxumab were approved in 2016. Delafloxacin, meropenem/vaborbactam, and ozenoxacin were approved in 2017. Plazomicin, eravacycline, sarecycline, omadacycline, and rifamycin were approved in 2018. Imipenem/cilastatin/ relebactam, pretomanid, lefamulin, and cefiderocol were approved in 2019. No FDA-approved drugs targeting resistant bacteria hit the market in 2020. Oritavancin was approved by the FDA in April 29, 2021.

Ceftazidime/avibactam is a combination of the thirdgeneration cephalosporin, ceftazidime, and the betalactamase inhibitor, avibactam. Ceftazidime inhibits peptidoglycan synthesis by inhibiting penicillin-binding proteins (PBPs), which results in cell wall instability and cell death. Avibactam is a synthetic, non-beta-lactamase inhibitor that inhibits the activity of class $\mathrm{A}$ and $\mathrm{C}$ betalactamases and some class D beta-lactamases. ${ }^{38}$ Avibactam protects ceftazidime from breakdown by the beta-lactamases produced by these drug-resistant GNB but does not inhibit subclass B1 beta-lactamases, such as New Delhi metallo-beta-lactamase (MBL), Verona integron-encoded MBL, and Imipenmase. ${ }^{39}$ Ceftazidime/avibactam is used to treat complicated intra-abdominal infections (cIAI) and cUTI caused by susceptible GNB. The adaptive bacteria, including MDR P. aeruginosa, carbapenem-resistant GNB, and extended-spectrum betalactamase-producing Enterobacterales (ESBL-E), are widespread. The most frequently encountered adverse reactions include hypersensitivity, diarrhea, and central nervous system reactions (such as seizures), which occur most often in patients with renal damage. ${ }^{40}$ According to clinical trials, the effect of Ceftazidime/avibactam is better than that of carbapenems. ${ }^{41}$ The combination therapy of ceftazidime/avibactam and metronidazole is recommended for cIAI. ${ }^{42}$ Although the combination has been available clinically for only a few years, cases of resistance to Ceftazidime/avibactam have already been reported. ${ }^{43}$

The new inhaled anthrax treatment, obiltoxaximab, is a monoclonal antibody against the protective antigen of Bacillus anthracis and is designed to neutralize the toxin produced by $B$. anthracis to prevent the bacterium from binding to the cellular receptor. ${ }^{44}$ Obiltoxaximab alone or in combination with antibiotics remarkably improved the survival rate of rabbits who inhaled a challenge dose of B. anthracis spores without interfering with immune development. ${ }^{45}$ The most frequently reported side effects of obiltoxaximab include headache, itching, upper respiratory tract infection, cough, stuffy nose, and hives, as well as bruising, swelling, and pain at the injection site. The label of obiltoxaximab carries a black box warning that the drug may cause allergic reactions, including anaphylactic shock. ${ }^{46}$

Bezlotoxumab is a human monoclonal IgG1 antibody against Clostridioides difficile toxin B30. Bezlotoxumab works by preventing the $\mathrm{B}$ toxin from binding to colon cells and thus prevent the development of $C$. difficile infection. Bezlotoxumab can reduce the proinflammatory reaction in vitro and reduce the damage to the colon explant tissue by neutralizing toxin B. It has no direct antibacterial activity against $C$. difficile and has low immunogenicity and good tolerability. ${ }^{47}$ However, it causes an unexplained increased risk of heart failure in patients with underlying congestive heart failure. Therefore, the bezlotoxumab adaptation population need to be further improved. $^{48}$

Delafloxacin, as a dual-targeted fluoroquinolone compound, was first approved by FDA on June 19, 2017 for clinical use in the treatment of acute bacterial skin and 
skin structure infections (ABSSSI). Delafloxacin can form a ternary complex with DNA and topoisomerase IV or DNA cyclotron to inhibit the formation of bacterial DNA superhelix and disrupt the DNA replication process. ${ }^{49}$ Delafloxacin protects against Gram-positive bacteria (GPB, such as MRSA) and GNB (including quinoloneresistant E. coli, $P$. aeruginosa, and $K$. pneumoniae) and is more active against MRSA than other fluoroquinolones. ${ }^{50}$ Its bactericidal ability under acidic environment is also more prominent than most approved zwitterionic fluoroquinolone drugs. Delafloxacin is well tolerated with a termination rate of only $0.9 \%$ because of side effects in a Phase 3 clinical trial. The common adverse reactions are gastrointestinal disorders, including nausea, diarrhea and vomiting. It did not cause QT prolongation and phototoxicity and has no adverse effects on liver function, renal function, or glucose utilization. ${ }^{51}$

Meropenem/vaborbactam is composed of the broadspectrum carbapenem, meropenem, and the betalactamase inhibitor, vaborbactam. Meropenem acts on PBPs and causes bacterial lysis by inhibiting cell wall biosynthesis. Vaborbactam is a new type of betalactamase inhibitor. It does not have any antibacterial activity but can protect meropenem from degradation by certain serine beta-lactamases without reducing meropenem activity. Meropenem/vaborbactam has a broadspectrum inhibitory activity against the members of the beta-lactamase family, and almost all (99\%) $K$. pneumoniae carbapenemase (KPC)-producing Enterobacteriaceae has in vitro activity. ${ }^{52}$ Vaborbactam has a strong inhibitory activity against type $\mathrm{A}$ and $\mathrm{C}$ betalactamases but not against type $\mathrm{B}$ and $\mathrm{D}$ beta-lactamases. ${ }^{53}$ In August 2017, the FDA approved Meropenem/vaborbactam for the treatment of adult patients with cUTIs, including pyelonephritis caused by certain bacteria. This drug has good efficacy against GNB, especially bacteria with beta-lactam antibiotic resistance, and has good safety and tolerability. ${ }^{54}$ The most common adverse effects of Meropenem/vaborbactam are headache, phlebitis or infusion site reactions, and diarrhea. Rare and serious adverse reactions include anaphylaxis and epilepsy. ${ }^{55}$

Ozenoxacin is a dual inhibitor of DNA helicase and topoisomerase IV and belongs to the non-fluoroquinolone class of drugs. Ozenoxacin was approved by the FDA in December 2017 for the treatment of impetigo caused by S. aureus or Streptococcus pyogenes in pediatric patients and adults older than 2 months of age. ${ }^{56}$ The drug kills bacteria by inhibiting bacterial DNA replicases, DNA cyclotron A, and topoisomerase IV. Ozenoxacin has excellent activity against $S$. aureus (including methicillinresistant isolates) and $S$. pyogenes. Adverse reactions include rosacea or seborrheic dermatitis. ${ }^{57}$

Plazomicin is a new generation of aminoglycoside antibiotics that can inhibit the $30 \mathrm{~S}$ subunits of bacterial ribosomes and then kill bacteria. Plazomicin is made by chemical modification on the basis of sisomicin, which avoids being damaged by the aminoglycoside-modifying enzyme (AME) and thus inactive. ${ }^{58}$ Plazomicin was approved by the FDA in June 2018 for the treatment of adult patients with cUTIs (including pyelonephritis) caused by certain Enterobacterales infections with very limited or no treatment options. The application was submitted to the European Medicines Agency (EMA) for review in June 2018. Plazomicin has antimicrobial activity against MDR Enterobacterales, $P$. aeruginosa, $S$. aureus (including MRSA), ESBL-E, carbapenemresistant Enterobacterales (CRE), polycolistin-resistant Enterobacterales, and AME-producing bacteria. ${ }^{59,60}$ Adverse reactions include nephrotoxicity (the incidence of nephrotoxicity is lower than that of colistin), diarrhea, hypertension, headache, nausea, vomiting, and hypotension. ${ }^{61}$

Eravacycline is a fully synthetic fluorocycline antibiotic that is a part of a novel tetracycline broad-spectrum antibiotic with C-7 and C-9 modifications to the D-ring of the tetracycline core. Similar to other tetracyclines, eravacycline inhibits bacterial protein synthesis by binding to the $30 \mathrm{~S}$ subunit of the ribosome. ${ }^{62}$ Eravacycline has broadspectrum antimicrobial activity against GNB, GPB, and anaerobic microorganisms, as well as against MDR bacteria, including MRSA, VRE, CRE, and Acinetobacter spp. that produce ESBL. ${ }^{63,64}$ The most common adverse reactions are infusion site reactions $(7.7 \%)$, nausea $(6.5 \%)$, vomiting (3.7\%), and diarrhea (2.3\%). ${ }^{65}$

Sarecycline is a tetracycline-derived oral antibiotic designed specifically for acne. It was approved by the FDA in 2018 for the treatment of inflammatory conditions associated with moderate to severe non-nodular acne. ${ }^{66}$ Sarecycline has strong anti-inflammatory activity against GPB, such as Cutibacterium acnes, and has minimal antiinflammatory activity against aerobic GNB. ${ }^{67}$ It has a low resistance rate in tetracycline-resistant $S$. aureus, as well as erythromycin-resistant and clindamycin-resistant bacteria. In clinical trials, adverse events were found in vulvovaginal mycosis $(0.8 \%)$ and vulvovaginal candidiasis $(0.6 \%)$ in 
less than $1 \%$ of female subjects; thus, the adverse events were small. ${ }^{68}$

Omadacycline is a novel tetracycline antimicrobial agent for the empirical treatment of community-acquired bacterial infections. The $\mathrm{C} 9$ and $\mathrm{C} 7$ sites of the $\mathrm{D}$ ring of the tetracycline core are chemically modified to stabilize the exhaust pump and ribosomal protective protein mechanism of tetracycline resistance. ${ }^{69}$ Similar to other tetracyclines, omadacycline inhibits bacterial protein synthesis by binding to the $30 \mathrm{~S}$ ribosomal subunit. Omadacycline provides a promising treatment plan for ABSSSI and community-acquired bacterial pneumonia (CABP). Moreover, omadacycline has a broad spectrum of activity against aerobic and anaerobic GPB and GNB; atypical bacteria; and antibiotic-resistant organisms, such as MRSA, methicillin-sensitive $S$. aureus (MSSA), and penicillin-resistant and MDR Streptococcus pneumoniae and VRE, but it has no activity against $P$. aeruginosa, Proteus spp., and Providencia spp. ${ }^{70}$ In clinical trials, the most common adverse reactions (incidence $\geq 2 \%$ ) were nausea, vomiting, infusion site reaction, increased alanine transaminase, increased aspartate transaminase, increased $\gamma$-glutamyltransferase, hypertension, headache, diarrhea, insomnia, and constipation. ${ }^{71}$

Rifamycin inhibits bacterial DNA-dependent RNA polymerase by inhibiting RNA synthesis. ${ }^{72}$ It was approved by the FDA in November 2018 for the treatment of noninvasive E. coli strains that cause traveler's diarrhea. In clinical trials, adverse reactions were constipation (3.5\%), headache (3.3\%), abdominal pain $(0.5 \%)$, and fever $(0.3 \%)$, and $1 \%$ of patients discontinued treatment. ${ }^{73,74}$

Imipenem/cilastatin/relebactam is a combination of imipenem, cilastatin, and relebactam. Imipenem/cilastatin is a combination antibiotic product that has been in use for decades under the brand names Primaxin and Tienam. Relebactam is a novel beta-lactamase inhibitor that protects Imipenem from degradation by certain serine betalactamases. Gram-negative strains resistant to imipenem became more sensitive to imipenem when combined with relebactam. In July 2019, the FDA approved Imipenem/ cilastatin/relebactam to treat cUTIs and cIAI caused by designated sensitive GPB for patients aged 18 years of age and older who have limited or no other treatment options. ${ }^{75}$ In addition, it was approved in 2020 for the treatment of hospital-acquired bacterial pneumonia (HABP) and ventilator-associated bacterial pneumonia (VABP) in adult patients caused by a variety of specific microorganisms, such as Enterobacter cloacae, E. coli,
K. pneumoniae, Clostridium perfringens, P. aeruginosa. The common adverse reactions of Imipenem/cilastatin/ relebactam include nausea, diarrhea, and headache. ${ }^{76,77}$

The novel compound, pretomanid, which is a part of a three-drug, six-month, all-oral regimen, bedaquiline-pretomanid-linezolid (BPAL), kills actively replicating Mycobacterium tuberculosis by blocking cell wall production under anaerobic conditions. Pretomanid is also active against non-replicating $M$. tuberculosis and acts as a respiratory poison to inhibit protein synthesis. ${ }^{78}$ It is used for the treatment of patients with extensively drugresistant (XDR) tuberculosis (TB) or MDR-TB (collectively referred to as "highly drug-resistant TB") who are drug intolerant or unresponsive. Treatment options and prognosis for people with highly drug-resistant $\mathrm{TB}$ are poor. Data from the pivotal Phase III NIX-TB trial showed that $90 \%$ of patients achieved negative sputum culture status 6 months after the completion of treatment with short-course fully oral BPAL. In the clinical trials of the BPAL program, peripheral neuropathy and anemia were the recognized adverse reactions. ${ }^{79-81}$

Cefiderocol is an injectable siderophore cephalosporin discovered and being developed by Shionogi \& Co., Ltd., Japan, and it has a unique mechanism of penetrating the cell membrane of GNB by entering the bacterial periplasmic space as a result of its siderophore-like property. ${ }^{82}$ Cefiderocol can inhibit the biosynthesis of bacterial cell walls and has strong bactericidal effect against all GNB, including carbapenem-resistant Gram-negative nonfermenting A. baumannii, P. aeruginosa, and refractory CRE. Cefiderocol has pioneered in the field of serious diseases, where mortality rates are high and medical needs are not met. FDA approved cefiderocol intravenous Injection and the Committee for Medicinal Products for Human Use of the EMA has also granted cefiderocol with accelerated assessment status. ${ }^{83-85}$ The common adverse reactions of cefiderocol include gastrointestinal disorders, hypertension, infusion site pain, and diarrhea. ${ }^{82}$

Lefamulin, an intravenous and oral formulation, was approved by the FDA in August 2019 for the treatment of adult CABP. It represents an important new, short-term, empirical monotherapy regimen. ${ }^{86}$ Lefamulin, a first-of-its -kind, system-administered semisynthetic pleuromutilin antibiotic that acts differently from other approved antibiotics. It can inhibit bacterial protein synthesis and thus inhibit bacterial growth by binding to the peptidyl transferase center of the $50 \mathrm{~S}$ subunit of the bacterial ribosome. ${ }^{87}$ Lefamulin has a targeted in vitro activity 
spectrum against the most common pathogenic Grampositive, Gram-negative, and atypical pathogens associated with CABP. Lefamulin also exerts activity against $S$. aureus, MRSA, and vancomycin-resistant $E$. faecium. ${ }^{88}$ The adverse effects of lefamulin include prolonged QT interval (increases the risk of kidney failure or liver dysfunction in patients), infusion reactions, diarrhea, nausea, hypokalemia, insomnia, and headaches. ${ }^{89}$

Ceftolozane/tazobactam is a combination of ceftolozane, a novel cephalosporin antibiotic, and tazobactam, a betalactamase inhibitor. It was approved by the FDA in 2014 for the treatment of adult patients with cIAI and cUTI and was approved by the FDA in 2019 for the treatment of adult patients with HABP and VABP caused by certain susceptible GNB. Ceftolozane had a strong inhibitory effect on PBPs. Compared with ceftazidime, imipenem, and ciprofloxacin, ceftolozane has demonstrated an 8-16-fold reduction in minimum inhibitory concentration against $P$. aeruginosa ${ }^{90}$ The efficacy of ceftolozane is limited by ESBLs and AMPC beta-lactamase. ${ }^{91}$ Therefore, tazobactam was added to ceftolozane to overcome this barrier and increase the in vitro activity against drug-resistant strains, such as betalactamase- and ESBL-producing strains (eg, E. coli, K. pneumoniae, and Proteus novelis); their combination also has certain inhibitory effects against AmpC inhibitory Enterobacterales and Citrobacter strains. Ceftolozane/tazobactam also has higher in vitro activity against Enterobacterales than existing cephalosporins but is still readily hydrolyzed by MBL and KPC enzymes. ${ }^{92-94}$ Ceftolozane/tazobactam has good in vitro activity against most Enterobacterales, including pathogens that produce ESBL, and has remarkable efficacy against $P$. aeruginosa. ${ }^{95}$

In addition, the FDA approved the anti-MRSA antibiotics dalbavancin and oritavancin in May and August 2014, respectively. ${ }^{96}$ Dalbavancin is a novel semisynthetic glycoseptide antibiotic and a derivative of the equivalent A40926. Dalbavancin has the same mechanism as vancomycin and teicoplanin, that is, it inhibits the biosynthesis of the cell wall of GPB. It is widely used for the treatment of skin and soft tissue infections. ${ }^{97}$ In vivo and in vitro studies have shown that dalbavancin has antimicrobial activity against GPB, including MRSA, MSSA, coagulase-negative staphylococci (CoNS), and Streptococcus. ${ }^{98}$ Dalbavancin is the first antibiotic approved by the FDA for the treatment of GPB (including MRSA) infection. It is used to treat ABSSSI caused by GPB (including MRSA). Oritavancin, an antibiotic for the treatment of GPB (including MRSA) infection, has been approved for the treatment of adult patients with ABSSSI caused by sensitive GPB (including MRSA). ${ }^{99,100}$

The US FDA approved oritavancin on March 12, 2021 for the treatment of ABSSSI caused by susceptible isolates of GPM, including MRSA. ${ }^{101}$ Oritavancin is a single-dose long-acting lipopeptides antibiotic made in a $1200 \mathrm{mg}$ vial in combination with $0.9 \%$ sodium chloride injection and $5 \%$ glucose sterile water for rapid bactericidal activity. Oritavancin is to be infused within 1 hour (ie, a single, 1-hour, $1200 \mathrm{mg}$ infusion provides a full course of ABSSSI treatment). ${ }^{102}$ Oritavancin has three bactericidal mechanisms: transpeptidase inhibition, transglycosylation inhibition, and cell membrane destruction. The efficacy and safety of oritavancin were demonstrated in the SOLO clinical trial of another oritavancin product. The experimental results showed that oritavancin was comparable to oritavancin in efficacy and safety. The common adverse reactions of oritavancin products are nausea, vomiting, diarrhea and other gastrointestinal symptoms, and headaches. The adverse reactions of oritavancin are manifested as hypersensitivity, pruritus, and chills. ${ }^{103}$

\section{Potential Drugs Against Drug-Resistant Bacteria}

Odilorhabdins (ODLs) are a novel ribosome targeted antibiotic produced by the nematode symbiotic bacterium, Xenorhabdus nematophila. ODL's overall mechanism of action is to interfere with protein synthesis, and the pattern it works depends on the concentration of the drug. ${ }^{104}$ Notably, its binding site is different from other inhibitors that target the $30 \mathrm{~S}$ ribosomal subunit, and the mutations that render the mitochondrial ribosome susceptible to aminoglycosides are not expected to affect the binding or action of ODLs. ${ }^{105}$ ODLs exhibit excellent broadspectrum antimicrobial activity against a broad range of GNB and GPB (K. pneumoniae, E. coli, Enterobacter aerogenes, E. cloacae, Proteus mirabilis, S. aureus, and Enterococcus faecalis), including drug-resistant strains that are difficult to treat, such as carbapenemaseproducing Enterobacterales. Moreover, ODLs were able to cure bacterial infections in animal models but did not exhibit bactericidal activity against cytotoxic in mammalian HepG2 and HK-2 cells. Their ability to cure bacterial infections in animal models and the novelty of their binding site made ODLs a promising candidate for new drug development. ${ }^{106,107}$ 
Teixobactin, a depsipeptide antibiotic derived from poorly cultivated soil microorganisms, is composed of 11 amino acids; this unique molecular structure confers its remarkable bacteriostatic activity. ${ }^{108,109}$ Its unique and novel antimicrobial mechanism is to bind to the conserved sequences of peptidoglycan precursor lipid II and teixobactin precursor lipid III on the bacterial cell wall such that the bacterial cell wall cannot synthesize toxins. It is capable of killing a variety of drug-resistant pathogenic bacteria. ${ }^{110}$ Teixobactin has a remarkable inhibitory activity against most GPB in vitro. ${ }^{111}$ It also has strong inhibitory activity against $M$. tuberculosis with long treatment cycles and high clinical costs. Teixobactin has profound inhibitory activity for a variety of MDR bacteria, such as MRSA and VRE. Teixobactin is not effective against most GNB but exhibits good activity against E. coli asmb1, which has a defective outer membrane permeability barrier. In vitro toxicology experimental studies showed that teixobactin has no substantial toxic side effects. ${ }^{112}$ Thus, teixobactin is considered the "star antibiotic". ${ }^{113,114}$ At present, the total chemical synthesis of teixobactin has been completed, and remarkable progress has also been made in the chemical synthesis of teixobactin analogs, which further drives the development of novel antibacterial drugs against drug-resistant strains. ${ }^{115}$

GNB have a double outer membrane that can block pathogens well, which makes them more difficult to kill than other types of bacteria. In the past 50 years, no new antibiotics against GNB have been approved for marketing. Arylomycin found in ordinary soil is a macrocyclic lipopeptide substance that can inhibit bacterial type I signal peptidase (SPase), which is a key membranebound enzyme that can decompose proteins and peptides. The active site of SPase, which is located between the cell membrane and outer membrane of GNB, greatly reduces the activity of arylomycin against GNB. ${ }^{116}$ G0775, the new molecule obtained after the structural optimization of arylomycin, is 500 times more active than arylomycin against drug-resistant strains. G0775 has a therapeutic effect on a variety of GNB infections, including MDR bacteria, and has strong in vitro antibacterial activity against ESKAPE pathogenic bacteria. The brand-new mode of action of G0775 is that it forms a covalent bond with lysine (K146) in the target, which enhances its binding force to the target. Moreover, G0775 reaches the target not through the conventional channel protein (porin) to penetrate the outer membrane. ${ }^{117}$
Malacidins are calcium-dependent antibiotics usually encoded in soil microorganisms. Unlike other calciumdependent antibiotics, malacidins interact with lipid II in a calcium-dependent manner. ${ }^{118}$ Although vancomycin also binds to lipid II, malacidin is active against vancomycin intermediates and vancomycin-resistant pathogens. ${ }^{119}$ Experiments show that malacidins have strong antibacterial activity against GPB resistant to commonly used clinical antibiotics, including vancomycin-resistant pathogens. In addition, malacidins have no obvious toxicity or hemolytic activity to mammalian cells. Therefore, it is a potential antibiotic for the treatment of drug-resistant bacteria that still needs further research. ${ }^{120}$

Researchers obtained the novel antibiotic, darobactin, a metabolite of luminescent Bacillus, from the screening of Photorhabdus isolates using the classic screening method in natural product research. ${ }^{121}$ Darobactin is a novel peptide formed by the rare closed-loop structure of seven amino acids and is encoded by the silencing operon, synthesized by the ribosome, and produced in very small quantities under laboratory conditions. In addition, a novel antimicrobial mechanism has been proposed, that is, darobactin binds to BamA protein located in the outer membrane of GNB, damages the outer membrane, and induces cell lysis. ${ }^{122}$ The compound exhibited good activity against wild-type and resistant Gram-negative pathogens, such as E. coli, $K$. pneumoniae, P. aeruginosa, Shigella, and Salmonella in vitro and in infected animal models and showed no cytotoxic effects. Therefore, this compound provides a very promising lead material for the development of new antibiotics.

Halicin is a broad-spectrum bactericidal antibiotic and the first antibiotic to be discovered by artificial intelligence without using any human assumptions. Halicin has inhibitory effect on the growth of E. coli, S. aureus, K. pneumoniae, and A. baumannii and has rapid bactericidal effect on M. tuberculosis and CRE. In a mouse model, halicin was also effective in treating $C$. difficile and pandrug resistant $A$. baumannii infections but had no antibacterial effect against $P$. aeruginosa. Halicin is antibacterial through a special mechanism; it can interfere with bacteria and prevent them from forming an electrochemical gradient across the membrane. It will cause bacterial death without such gradient. ${ }^{123}$ However, the process of reshaping the electrochemical gradient is very complicated, which also prevents the generation of drug resistance to the greatest extent. Halicin was discovered by building a deep neural network model with empirical data from 2335 FDA- 
approved drugs and natural molecules with a wide range of biological activity. The resulting model was then applied to predict antimicrobial compounds in drug recovery centers, and halicin was finally identified as a broad-spectrum bactericidal antibiotic. The antimicrobial compounds identified by this method are structurally far different from known antibiotics; this finding emphasizes the utility of deep learning methods. The antibiotic library can be expanded and new ideas can be provided for the development of subsequent antibiotics by discovering antimicrobial molecules with different structures. ${ }^{124,125}$

Pseudouridimycin (PUM), produced by microorganisms in soil samples, is a novel inhibitor antibiotic and the first nucleoside analog inhibitor. ${ }^{126,127}$ PUM competes with uridine triphosphate to obtain the RNA polymerase (RNAP) active site and inhibit bacterial RNAP by blocking transcription. Although its antimicrobial mechanism is not new, it is unique in the sense that PUM selectively inhibits bacterial RNAP rather than human RNAP. Moreover, PUM has a different binding site compared with other RNAP inhibitors, such as rifampicin and fidaxomicin, which greatly avoids the occurrence of cross-drug resistance. ${ }^{128}$ Studies have shown that PUM has antibacterial activity against GPB, GNB, and even more lethal pathogens (such as E. coli, Acinetobacter spp., and
Pseudomonas spp., especially MDR strains). Its mechanism of action made the development of bacterial resistant very difficult. Therefore, PUM is expected to a become true broadspectrum antibiotics for clinical application. ${ }^{129}$

Table 1 summarizes the source, activity, against, mechanism of action and highlights of these potential drugs, and the chemical structures summarized in Figure 2.

\section{New Molecules Synthesized by Chemical Modification}

OTB-021(5-methyl-7-(3-nitro-1,2,4-triazol-1-yl)-1,2,4-triazolo[1,5-a]pyrimidine) is a compound that has specific activity against the H37RV strain, which is sensitive to M. tuberculosis drugs, but this compound has no activity against other GNB or GPB. ${ }^{130}$ OTB-021 isomer showed reverse biological activity, which can inhibit the growth of all ESKAPE pathogens but is inactive against M. tuberculosis. The results will help to develop new effective drugs against diseases caused by drug-resistant bacteria. ${ }^{131}$

NAC-3, a new cephalosporin compound, was synthesized using cephalomycin $\mathrm{C}$ as the precursor; NAC-3 retained the antibacterial activity of its precursor and possessed improved stability against beta-lactamase with a $7 \alpha$

Table I Potential Drugs Against Drug-Resistant Bacteria with Their Reported Mechanism

\begin{tabular}{|c|c|c|c|c|}
\hline Name & Source & Activity Against & Mechanism of Action & Highlights \\
\hline $\begin{array}{l}\text { Odilorhabdins } \\
\text { (ODLs) }\end{array}$ & $\begin{array}{l}\text { From the nematode } \\
\text { symbiotic bacterium } \\
\text { X. elegans }\end{array}$ & $\begin{array}{l}\text { GNB and GPB, including } \\
\text { carbapenemase producing } \\
\text { Enterobacteriaceae }\end{array}$ & $\begin{array}{l}\text { Inhibition of protein } \\
\text { synthesis }\end{array}$ & $\begin{array}{l}\text { - A novel binding site; } \\
\text { - Drug concentration affects } \\
\text { inhibition patterns }\end{array}$ \\
\hline Teixobactin & $\begin{array}{l}\text { From poorly cultivated } \\
\text { soil microorganisms }\end{array}$ & GPB, including MDR strains & $\begin{array}{l}\text { Inhibition of cell wall } \\
\text { synthesis }\end{array}$ & $\begin{array}{l}\text { - Novel antimicrobial mechanism; } \\
\text { - No significant toxic side effects }\end{array}$ \\
\hline G0775 & $\begin{array}{l}\text { Optimized the } \\
\text { structure of } \\
\text { arylomycin }\end{array}$ & $\begin{array}{l}\text { GNB, including ESKAPE } \\
\text { pathogenic bacteria }\end{array}$ & Inhibition of SPase & $\begin{array}{l}\text { - The way to reach the target is } \\
\text { novel }\end{array}$ \\
\hline Malacidins & $\begin{array}{l}\text { From the soil } \\
\text { microorganisms }\end{array}$ & GPB, including MDR strains & $\begin{array}{l}\text { Interaction with lipid II in } \\
\text { a calcium-dependent } \\
\text { manner }\end{array}$ & - No cytotoxic effects \\
\hline Darobactin & $\begin{array}{l}\text { From the screening of } \\
\text { Photorhabdus isolates }\end{array}$ & GNB, including MDR strains & $\begin{array}{c}\text { Damage in the outer } \\
\text { membrane }\end{array}$ & $\begin{array}{l}\text { - Novel antimicrobial mechanism; } \\
\text { - No cytotoxic effects }\end{array}$ \\
\hline Halicin & $\begin{array}{l}\text { From artificial } \\
\text { intelligence }\end{array}$ & $\begin{array}{l}\text { GPB and GNB, including MDR } \\
\text { strains }\end{array}$ & $\begin{array}{l}\text { Interruption of the } \\
\text { transmembrane } \\
\text { electrochemical gradient }\end{array}$ & - Novel antimicrobial mechanism \\
\hline $\begin{array}{l}\text { Pseudouridimycin } \\
\text { (PUM) }\end{array}$ & $\begin{array}{l}\text { From the } \\
\text { microorganisms in soil } \\
\text { samples }\end{array}$ & $\begin{array}{l}\text { GPB and GNB, including MDR } \\
\text { strains }\end{array}$ & $\begin{array}{l}\text { Inhibition of bacterial } \\
\text { RNAP by blocking } \\
\text { transcription }\end{array}$ & $\begin{array}{l}\text { - Selectively inhibit bacterial } \\
\text { RNAP; } \\
\text { - Different binding site }\end{array}$ \\
\hline
\end{tabular}


<smiles>[R2]C(CN)CC[C@H](NC(=O)/C(=C/CCNC(=N)N)NC(=O)[C@H](CCC([R1])CN)NC(=O)[C@H](Cc1cnc[nH]1)NC(=O)[C@@H]1CCCN1C(=O)[C@H](CCCN)NC(=O)CNC(=O)[C@H](NC(=O)[C@H](NC(=O)[C@H](N)CCCCN)[C@@H](O)CN)[C@@H](O)CN)C(=O)NCCCN</smiles>

\section{Odilorhabdins (ODLs)}<smiles>N=C(N)NCC(=O)N(O)C(CCC(N)=O)C(=O)NC[C@H]1O[C@@H](c2c[nH]c(=O)[nH]c2=O)[C@H](O)[C@@H]1O</smiles>

Pseudouridimycin(PUM)

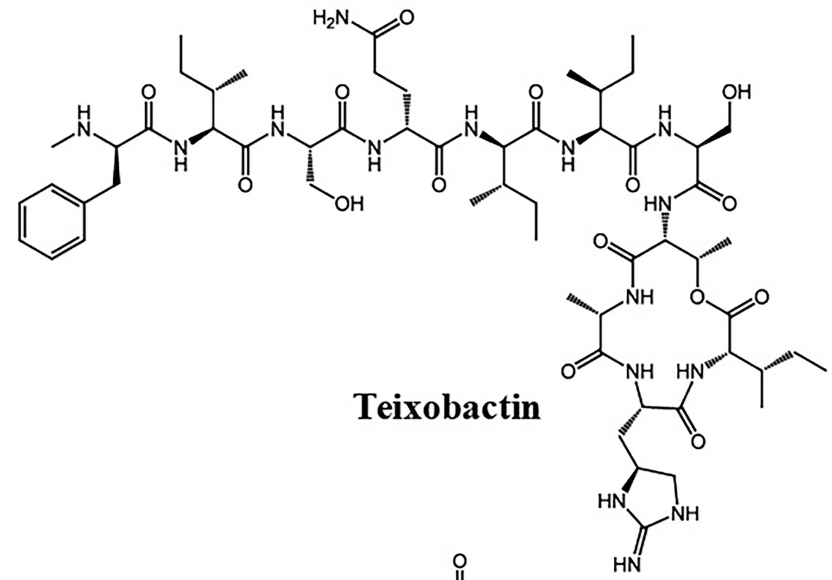<smiles>Cc1nc(-c2ccc(C(C)(C)C)cc2)ncc1C(=O)NC(CCN)C(=O)N(C)C(C(=O)NC(C)C(=O)NC(Cc1ccc(OCCN)c(OCCN)c1)C(=O)NCC#N)c1cccc(OCCN)c1</smiles>

G0775

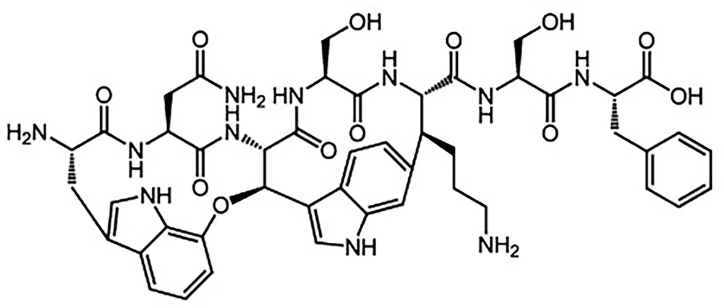

\section{Darobactin}<smiles>Nc1nnc(Sc2ncc([N+](=O)[O-])s2)s1</smiles>

Figure 2 Potential drugs against drug-resistant bacteria with their chemical structure. trans methoxy in the beta-lactam ring. In addition, NAC-3 because of its cephalomycin C parent nucleus. ${ }^{132-135}$ The has strong hydrophilicity, which also renders strong anti- antibacterial activity of NAC-3 against GPB, including bacterial activity, especially against anaerobic bacteria, MRSA, MSSA, methicillin-resistant Staphylococcus 
epidermidis, and methicillin-sensitive S. epidermidis, is remarkably better than that of latamoxef and cefepime, but not strong enough against E. faecalis and E. faecium. Its antimicrobial activity against GNB, including $E$. coli (ESBLs, non-ESBLs), K. pneumoniae (ESBLs, nonESBLs), A. baumannii, and $P$. aeruginosa, is low, but it has outstanding anti-MRSA activity, which has important clinical application value. Moreover, NAC-3 has good protective effect on the systemic infections caused by $S$. aureus in vivo, and its therapeutic effect is better than that of the commonly used clinical antibiotics, cefepime and cephalosporin. Hence, it became a new antibiotic candidate for anti-MRSA infection and provided a basis for the further research and development of new cephalosporin compounds. ${ }^{136}$

Serafim et al synthesized a new synthetic 1,3-bis(aryloxy)propan-2-amine, which has antibacterial activity against GPB, including MRSA. In the future, the continuous optimization of the structure of the compound may also expand the antibacterial spectrum. ${ }^{137}$

Amino acid-conjugated polymers (ACPs) are a new type of molecule developed by chemically linking glycine with polymers. ACPs have high antibacterial activity against MDR A. baumannii, have no toxicity to human cells, and does not easily develop drug resistance. Further research on the efficacy of this molecule is needed in animal models. ${ }^{138}$ Based on in vitro studies, ACPs have great potential to be developed as future therapeutics. ${ }^{139}$ As the hydrophobicity of the amino acid side chain increases, its antibacterial activity and toxicity increase, which could provide new ideas for the subsequent discovery of new antibiotics against drug-resistant bacteria. ${ }^{140}$

\section{Combination Therapy}

Taniborbactam is the first beta-lactamase inhibitor that has direct inhibitory activity on type A, B, C, and D enzymes. ${ }^{141}$ The combined application of taniborbactam and the fourth-generation cephalosporin, cefepime, may be used to treat the infections caused by carbapenem-resistant pathogens, such as CRE and $P$. aeruginosa; Gram-negative and Gram-positive susceptible pathogens; and bioterrorist pathogens, such as Burkholderia spp. ${ }^{142}$

Synergistic effects between plazomicin and piperacillin/tazobactam or ceftazidime were observed in chessboard studies. These studies suggest that plazomicin has the potential to be used as a monotherapy and combination therapy for the treatment of severe infections caused by MDR Gram-negative Enterobacterales. ${ }^{143}$
In the combination therapy described by Procopio et al, the lectin, casuL, is an antimicrobial membrane agent against some Staphylococcus isolates obtained from animals with mastitis. In addition, the synergistic activity of casuL, when used in combination with antibiotics, supports the need for new studies to determine the feasibility of this approach in the treatment of goat and bovine mastitis. $^{144}$

The drug efflux mechanism and outer membrane permeability barrier of GNB act synergistically to form intrinsic drug resistance. ${ }^{145}$ Small molecule adjuvants may be used as a strategy to restore the activity of antibiotics against drug-resistant pathogens. ${ }^{146}$ Efflux pump inhibitors (EPIs) block the efflux of antibiotics, but their efficiency in penetrating the outer membrane and resisting efflux is low. Combination with tobramycin carrier can enhance the synergistic effect and effectiveness of EPIs on MDR GNB and inhibit the development of drug resistance. This mechanism provides a strategy for developing more effective adjuvants to address antibiotic resistance in MDR GNB. ${ }^{147-149}$ Tobramycin has been approved as an adjuvant beta-lactamase inhibitor for clinical use to prevent the inactivation of beta-lactam antibiotics. ${ }^{150}$

Recent studies have shown that the combination of bacteriophage and antibiotic therapy can provide a new way to treat the infection caused by the MDR strains of A. baumannii. A. baumannii, which can avoid bacterial killing, produce a sample capsule, and have thick outer layers for self-protection. ${ }^{151}$ However, the phage used by the researchers can use the same capsule as an entrance to enter the bacteria and exert bacterial killing. Thus, A. baumannii will stop the production of capsule and become resensitized to antibiotics to escape the phage role. Animal experiments have shown that this method has a good therapeutic effect. ${ }^{152}$

\section{Drug Repurposing}

Fosfomycin was discovered early but used less frequently. It currently has a wide range of activities against GNB and GPB, including MDR organisms, such as MRSA, VRE, ESBL-E, and CRE. ${ }^{153}$ The broad-spectrum and safety of fosfomycin provide a great prospect for children with MDR organism infection. If fosfomycin is used alone, it may develop rapid drug resistance. However, fosfomycin can have a synergistic effect with other antibiotics in combination therapy, in which cross-resistance is not common; therefore, it needs to be used with caution to maintain the susceptibility of bacteria to fosfomycin. 
In recent years, polymyxin B has been re-emphasized as the last resort for the treatment of MDR and XDR GNB infections. ${ }^{154}$ Polymyxin plays an important role in the recurrence of GNB infection, especially MDR P. aeruginosa, A. baumannii, and K. pneumoniae. ${ }^{155}$ The adverse reactions of polymyxin include nephrotoxicity, neurotoxicity, and congenital abnormalities. ${ }^{156}$

Research has revealed a new type of target for the treatment of drug-resistant TB using anti-platelet drugs, which may help the body's immune system fight off drugresistant TB. Researchers have discovered for the first time in an animal model that platelets may worsen the symptoms of TB. ${ }^{157}$ Moreover, the use of antiplatelet drugs may help the body's immune system to resist drug-resistant TB. Therefore, the antiplatelet drug, aspirin, can be used as an affordable drug candidate for TB treatment. ${ }^{158}$ In addition, the use of FDA-approved reactive oxygen species (ROS)reducing drugs prevents antibiotic-induced resistance mutations, but further preclinical trials are still needed to evaluate the effectiveness of such drugs. ${ }^{159}$

\section{Immunotherapy}

The positive effects of antibodies against MDR bacterial infections were discovered in early animal experiments; therefore, antibodies have attracted increasing attention. ${ }^{160}$ Researchers have developed antibodies from the blood of healthy individuals that can protect the body against a variety of $K$. pneumoniae subgroups and other bacteria. The chimeric antibody, pagibaximab, has a certain inhibitory effect on MRSA. ${ }^{161}$ The monoclonal antibody, bezlotoxumab, against $C$. difficile toxin was approved by the FDA and the EMA in 2017 for the treatment of adult C. difficile infections. ${ }^{162}$ Immune adjuvants can enhance immunogenicity and antibody titer, change the type of antibody produced, and cause or enhance delayed hypersensitivity. Existing research reports that antibodies play an auxiliary role in the treatment of drug-resistant bacterial infections. ${ }^{163}$

Antimicrobial peptides are a potentially effective therapy. Regardless of whether the bacteria are resistant or not, they kill the bacteria by destroying the bacterial cell membrane. ${ }^{164}$ Researchers found that engineered cationic AMPs have a wide range of activities against MDR bacteria. ${ }^{165}$ However, their stability is still an important concern. ${ }^{166}$ The antibacterial peptide, OH-Cath30, identified in king cobra venom has strong antibacterial activity. In vivo and in vitro studies found that $\mathrm{OH}-\mathrm{Cath} 30$ and its D-analogs have strong antibacterial activity against almost all GPB and GNB. It has the highest bactericidal activity against MDR A. baumannii and MRSA. OH-Cath30, ciprofloxacin, and levofloxacin have a synergistic effect on drug-resistant $P$. aeruginosa. ${ }^{167}$ The overall efficacy of OH-Cath 30 and its analogs is higher than that of the nine commonly used antibiotics. Therefore, OH-Cath30 is a promising drug candidate for the treatment of various bacterial infections that are resistant to many conventional antibacterial drugs. ${ }^{168} \mathrm{~A}$ recently reported adjuvant uses Cremophor EL-35 as a surfactant and propylene glycol as a co-surfactant. The adjuvant can increase the specific immune response of serum IgG and related subclasses and increase the survival rate of MRSA-infected mice. ${ }^{169}$ Tocotrienols (T3s) is a little-known vitamin $\mathrm{E}$ isomer and has been recognized as an immunomodulator. In a mouse model of MRSA-induced wound infection, the use of T3S combined with daptomycin remarkably improved the efficacy of daptomycin. ${ }^{170}$ Among natural products, essential oils (EOs) have strong antibacterial ability against GNB and GPB. ${ }^{171,172}$ They can directly kill and sensitize bacteria and are often used in the prevention and control of microbial infections. ${ }^{173-177}$ In addition, EOs are considered a powerful antibacterial or drug resistance reversal agent against resistant strains led by ESKAPE. ${ }^{178-180}$ Moreover, EOs and antibacterial drugs (especially oxacillin against MRSA) show a high synergistic effect at subinhibitory concentrations, which lays the foundation for the subsequent development of drugs against drugresistant bacteria. ${ }^{181}$ A cytokine protein called IL-17 is essential to turn on the host's defence against staphylococcal infections. In a mouse model of $S$. aureus skin infection, IL-17 response was mediated by $\gamma \delta \mathrm{T}$ cells, which suggests that the cloned $\mathrm{V} \gamma 6+\mathrm{V} \delta 4+\mathrm{T}$ cells have a broad and important role in immunity against $S$. aureus or MRSA skin infections. ${ }^{182}$ Studies have found that the binding domain of autolyzed protein and lysosome as a peptidoglycan hydrolase can be fused to the fragment crystallizable region of human $\mathrm{IgG}$ to form a fully functional homodimer (or "lysibody") and can be specifically targeted in MRSA. ${ }^{183,184}$

\section{Other Therapies}

The quorum sensing (QS) mechanism enhances the mutual communication and virulence effects of microbial communities and ultimately leads to the emergence of antibiotic resistance. ${ }^{185}$ With the increase in resistance to existing antibiotics and antifungal drugs, new strategies rely on inhibiting communication and virulence factors rather 
than killing or inhibiting the growth of microorganisms. ${ }^{186}$ These compounds are also known as QSI. ${ }^{187}$ QSI can be an important antibacterial target for infectious diseases caused by the QS mechanism of GNB and GPB to prevent, inhibition, or treat the infectious diseases caused by resistant bacteria. ${ }^{188}$ Indole is a widely existing QS signaling molecule. ${ }^{189}$ Bacterial drug resistance mediated by signal molecules is an emerging mechanism that has received much attention in recent years. Researchers reported for the first time that the indole-mediated reversal of the inherent antibiotic resistance of Lysobacter spp. is closely related to a new type of BTUD bifunctional transporter. ${ }^{190}$ This study also provides a new way to eliminate drugresistant bacteria.

In addition to their excellent activity on biofilms, phages also have the advantages of rapid bacteria killing, have low chance of developing drug resistance, and have synergistic activity with other antibiotics and lysine. ${ }^{191}$ Phage lysin is also being developed for specific GPB, such as S. pneumoniae, S. aureus, and S. pyogenes, as well as Gram-negative bacilli, such as $P$. aeruginosa, A. baumannii, and Enterobacterales. ${ }^{192}$ The use of some bacteriophages in combination with antibiotics offers hope that the antibiotics that previously lost their antibacterial effect against drug-resistant bacteria will regain their role in killing these bacteria. ${ }^{193}$ Nanoparticles are used as a drug surface coating agent to help the drug to penetrate the outer membrane of GNB and be released; these nanoparticles are called the "Trojan Horse" and greatly reduce the blocking of drugs by biofilms and drug transporters. ${ }^{194,195}$ Coagulation factors have the ability to hydrolyze the necessary lipopolysaccharides in bacterial cell membranes, which may be expected to help defend against GNB. ${ }^{196}$ Studies have shown that coagulation factors VII, IX, and $\mathrm{X}$ may be effective against MDR pathogens. ${ }^{197,198}$

Studies have shown that the water and methanol extracts of Piper spp. and Smilax spp. can effectively reverse the MDR of bacteria by removing the R-plasmid carried by MDR strains and make the bacteria sensitive to antimicrobial agents. These resources can potentially curb plasmid-mediated MDR. ${ }^{199}$

For the patients who cannot benefit from targeted antibiotic therapy with $C$. difficile, fecal transplantation or microbial replacement therapy will refill the intestines with a variety of microorganisms. ${ }^{200}$ These microorganisms may prevent $C$. difficile spores from germinating and spreading diseases through its toxin. Transplantation may be performed through enema, capsule, and direct infusion. Researchers found that stopping Salmonella from producing mucus weakens bacterial communities, which can then be mechanically washed away and are more likely to be killed by antibiotics, disinfectants, or the immune system. ${ }^{201}$ The collapsed nature of the dry capsule of GBP was found through the exploration of their cell wall structure. ${ }^{202,203}$ This finding overturns the previous related theories about the structure of the outer membrane of bacteria and provides new ideas for the later development of new methods to resist antibiotic resistance. ${ }^{204}$

\section{Discussion}

The development of antibiotics has given humans a weapon against bacteria. However, drug-resistant bacteria have emerged in an endless stream, people gradually lost control of the bacteria that invade the human body, and global incurable crisis reappeared because of the development of drug resistance of pathogens and the abuse of antibiotics by humans. At present, the abuse of antibiotics has not been completely controlled and is still happening in varying degrees in different regions around the world. Therefore, in the face of increasingly tense global health issues that are closely related to the safety of human life, the issue of combating drug-resistant bacteria needs to be formally raised and emphasized again.

From 2015 to 2020, 16 antibiotic drugs, including 5 compound drugs, namely, Ceftazidime/avibactam, meropenem/vaborbactam, imipenem/cilastatin/relebactam, pretomanid, and ceftolozane/tazobactam, were approved by the FDA. Among them, ceftazidime/avibactam, meropenem/vaborbactam, imipenem/cilastatin/relebactam, and ceftolozane/tazobactam are combinations of antibacterial drugs and beta-lactamase inhibitors and have good activity against drug-resistant bacteria, whereas pretomanid has good anti-TB activity.

Moreover, potential drugs against drug-resistant bacteria are also of great importance to the development of antimicrobial drugs for resistant bacteria in the future. ODL, halicin, and PUM are promising as broad-spectrum antibiotics. Among them, the ODL target is novel and has good activity against drug-resistant strains; halicin interferes with the formation of bacterial energy, has inhibitory effect on certain resistant bacteria, but has no bactericidal effect on P. aeruginosa; and PUM has a novel target, blocks transcription, and is active against MDR strains. Teixobactin, G0775, and darobactin have novel antibacterial mechanisms. Teixobactin inhibits cell wall synthesis, 
has remarkable inhibitory activity against most GPB and a variety of drug-resistant bacteria, but cannot effectively resist GNB. G0775 penetrates the outer membrane in a special way to inhibit bacterial SPase with a new mechanism to kill a variety of GNB, including MDR bacteria. Darobactin destroys the outer membrane of bacteria and shows good activity against wild-type and drugresistant GNB in vitro and in animal models of infection.

In addition to drugs against drug-resistant bacteria derived from natural products, chemically modified synthetic new molecules have also become an important way for the development of drugs against drug-resistant bacteria. OTB-021 is only sensitive to M. tuberculosis and has no effect on Gram-positive or Gram-negative pathogens, but its two isomers are just the opposite. Further NAC-3 has outstanding anti-MRSA activity. The new synthetic 1,3-bis(aryloxy)propan-2-amines have biological activity against GPB. The ACPs developed by chemical linkage have high antibacterial activity against MDR A. baumannii.

Combination therapy and the repurposing of old drugs have opened another door to the exploration of drugs and strategies against drug-resistant bacteria and are a promising way to extend the service life of existing antibacterial drugs. Techniques, such as phage therapy, nanotechnology, and fecal transplantation, are gradually being used to overcome the infections caused by resistant bacteria. In addition, phage therapy has rapid killing kinetics, specificity for pathogens, low chance of drug resistance, and synergistic activity with other antibiotics and lysine. At present, nanotechnology is gradually emerging in the treatment of drug-resistant bacterial infections. Fecal transplantation or microbial replacement therapy will help patients who cannot benefit from $C$. difficile targeted antibiotic therapy and prevent $C$. difficile spores from germinating and spreading diseases through its toxin.

\section{Conclusion}

This review comprehensively summarizes the drugs that have been developed against drug-resistant bacteria, the possible potential drugs, and other approaches that can be applied to fight drug-resistant bacteria in addition to antibiotics. Many potential drugs need more experiments to verify their efficacy, and the antibacterial mechanism of most potential drugs is still unclear. FDA-approved drugs against drug-resistant bacteria account for a small proportion of all approved drugs. Researchers search for new drugs or new molecules that can delay or reduce the emergence of drug-resistant bacteria through the combination of drugs, repurposing old drugs, and library searches and provide different solutions to the serious problem of bacterial resistance. In summary, it is likely that the current crisis of drug-resistant bacteria will not be resolved by a single new product or therapy. And it is believed that, a multidisciplinary research involving experts from various fields will more conductive to resolve the crisis and lay a solid road for the clinical treatment of patients infected with drug-resistant bacteria.

\section{Acknowledgments}

This work was supported by The National Nature Science Foundation of China (grant nos. 81860653 and 82060654); The Science and Technology Foundation of Shaanxi Province [2020JM-550, 2020JM-545, 2020JM-549, and 2021JM-416]; Open Project Foundation of Key Laboratory of noncoding RNA and drugs in Universities of Sichuan Province [FB19-01 and FB20-02]; Open project Shaanxi Engineering and Technological Research Center for Conversation and Utilization of Regional Biological Resources (sxgczx-2019-02); Initial Scientific Research Fund of Yan'an University (YDBK201850 and YDBK2018-43), and Research Program of Yan'an University (YDZ2019-09 and YDZ2020-17).

\section{Author Contributions}

All authors made substantial contributions to conception and design, acquisition of data, or analysis and interpretation of data; took part in drafting the article or revising it critically for important intellectual content; agreed to submit to the current journal; gave final approval of the version to be published; and agree to be accountable for all aspects of the work.

\section{Disclosure}

The authors report no conflicts of interest in this work.

\section{References}

1. Bennett JW, Chung KT. Alexander Fleming and the discovery of penicillin. Adv Appl Microbiol. 2001;49:163-184.

2. Katz L, Baltz RH. Natural product discovery: past, present, and future. $J$ Ind Microbiol Biotechnol. 2016;43(2-3):155-176. doi:10.1007/ s10295-015-1723-5

3. Davies J, Davies D. Origins and evolution of antibiotic resistance. Microbiol Mol Biol Rev. 2010;74(3):417-433. doi:10.1128/ MMBR.00016-10

4. Hutchings MI, Truman AW, Wilkinson B. Antibiotics: past, present and future. Curr Opin Microbiol. 2019;51:72-80. doi:10.1016/j. mib.2019.10.008 
5. Power E. Impact of antibiotic restrictions: the pharmaceutical perspective. Clin Microbiol Infect. 2006;12(Suppl 5):25-34. doi:10.1111/j.1469-0691.2006.01528.x

6. Wetzel C, Lonneman M, Wu C. Polypharmacological drug actions of recently FDA approved antibiotics. Eur J Med Chem. 2021;209:112931. doi:10.1016/j.ejmech.2020.112931

7. Christaki E, Marcou M, Tofarides A. Antimicrobial resistance in bacteria: mechanisms, evolution, and persistence. J Mol Evol. 2020;88(1):26-40. doi:10.1007/s00239-019-09914-3

8. World Health Organization. La Resistencia a Los Antimicrobianos. Suiza: World Health Organization; 2019.

9. O’Neill J. Tackling Drug-Resistant Infections Globally: Final Report and Recommendations. Government of the United Kingdom; 2016.

10. Antibiotic/antimicrobial resistance (AR/AMR). Available from: https://www.cdc.gov/drugresistance/index.html. Accessed July 20, 2020.

11. Cassini A, Högberg LD, Plachouras D, et al. Attributable deaths and disability-adjusted life-years caused by infections with antibiotic-resistant bacteria in the Eu and the European economic area in 2015: a population-level modelling analysis. Lancet Infect Dis. 2019;19(1):56-66. doi:10.1016/S1473-3099(18)30605-4

12. World Health Organization. Superbugs. Why We Need Action Now. World Health Organization; 2016.

13. Thompson ND, LaPlace L, Epstein L, et al. Prevalence of antimicrobial use and opportunities to improve prescribing practices in U.S. nursing homes. $J$ Am Med Dir Assoc. 2016;17 (12):1151-1153. doi:10.1016/j.jamda.2016.08.013

14. Woolhouse M, Waugh C, Perry MR, Nair H. Global disease burden due to antibiotic resistance - state of the evidence. J Glob Health. 2016;6(1):10306. doi:10.7189/jogh.06.010306

15. Santhakumari S, Ravi AV, Logalakshmi R. Targeting Quorum sensing mechanism: an alternative anti-virulent strategy for the treatment of bacterial infections. Int $J$ Food Microbiol. 2018;281:60-71. doi:10.1016/j.ijfoodmicro.2018.05.024

16. Gil-Gil T, Laborda P, Sanz-García F, Hernando-Amado S, Blanco P, Martínez JL. Antimicrobial resistance: a multifaceted problem with multipronged solutions. Microbiologyopen. 2019;8 (11):e945. doi:10.1002/mbo3.945

17. Xu WC, Silverman MH, Yu XY, Wright G, Brown N. Discovery and development of DNA polymerase iiic inhibitors to treat gram-positive infections. Bioorg Med Chem. 2019;27 (15):3209-3217. doi:10.1016/j.bmc.2019.06.017

18. Antibiotic Research UK; 2019. Available from: https://www.antibio ticresearch.org.uk/about-antibiotic-resistance. Accessed November 27, 2021.

19. Bartlett JG, Gilbert DN, Spellberg B. Seven ways to preserve the miracle of antibiotics. Clin Infect Dis. 2013;56(10):1445-1450. doi:10.1093/cid/cit070

20. DeNegre AA, Ndeffo Mbah ML, Myers K, Fefferman NH. Emergence of antibiotic resistance in immunocompromised host populations: a case study of emerging antibiotic resistant tuberculosis in aids patients. PLoS One. 2019;14(2):e0212969. doi:10.1371/journal.pone.0212969

21. Brown ED, Wright GD. Antibacterial drug discovery in the resistance era. Nature. 2016;529(7586):336-343. doi:10.1038/ nature 17042

22. Fairlamb AH, Gow NA, Matthews KR, Waters AP. drug resistance in eukaryotic microorganisms. Nat Microbiol. 2016;1 (7):16092. doi:10.1038/nmicrobiol.2016.92

23. Hoenes K, Bauer R, Meurle T, Spellerberg B, Hessling M. Inactivation effect of violet and blue light on eskape pathogens and closely related non-pathogenic bacterial species - a promising tool against antibiotic-sensitive and antibiotic-resistant microorganisms. Front Microbiol. 2020;11:612367. doi:10.3389/ fmicb.2020.612367
24. Rice LB. Federal funding for the study of antimicrobial resistance in nosocomial pathogens: no eskape. J Infect Dis. 2008;197 (8):1079-1081. doi:10.1086/533452

25. Biggest threats and data. Available from: https://www.cdc.gov/ drugresistance/biggest-threats.html. Accessed March 2, 2021.

26. Ramirez MS, Tolmasky ME. Aminoglycoside modifying enzymes. Drug Resist Updat. 2010;13(6):151-171. doi:10.1016/ j.drup.2010.08.003

27. Groves MD, Crouch B, Coombs GW, et al. Molecular epidemiology of methicillin-resistant staphylococcus aureus isolated from Australian veterinarians. PLoS One. 2016;11(1):e0146034. doi:10.1371/journal.pone.0146034

28. Van Bambeke F, Balzi E, Tulkens PM. Antibiotic efflux pumps. Biochem Pharmacol. 2000;60(4):457-470. doi:10.1016/S00062952(00)00291-4

29. Bao M, Zhang L, Liu B, et al. Synergistic effects of anti-mrsa herbal extracts combined with antibiotics. Future Microbiol. 2020;15:1265-1276. doi:10.2217/fmb-2020-0001

30. Piątkowska E, Piątkowski J, Przondo-Mordarska A. The strongest resistance of Staphylococcus aureus to erythromycin is caused by decreasing uptake of the antibiotic into the cells. Cell Mol Biol Lett. 2012;17(4):633-645. doi:10.2478/s11658-012-0034-3

31. Chang S, Sievert DM, Hageman JC, et al. Infection with vancomycin-resistant staphylococcus aureus containing the vana resistance gene. $N$ Engl $J$ Med. 2003;348(14):1342-1347. doi:10.1056/NEJMoa025025

32. Peraman R, Sure SK, Dusthackeer VNA, et al. Insights on recent approaches in drug discovery strategies and untapped drug targets against drug resistance. Futur J Pharm Sci. 2021;7(1):56. doi:10.1186/s43094-021-00196-5

33. Ghodhbane H, Elaidi S, Sabatier JM, Achour S, Benhmida J, Regaya I. Bacteriocins active against multi-resistant gram negative bacteria implicated in nosocomial infections. Infect Disord Drug Targets. 2015;15(1):2-12. doi:10.2174/1871526514666140522113337

34. Oliveira J, Reygaert WC. Gram negative bacteria. In: Statpearls. Treasure Island (FL): StatPearls Publishing Copyright (C) 2020, StatPearls Publishing LLC.; 2020.

35. Motbainor H, Bereded F, Mulu W. Multi-drug resistance of blood stream, urinary tract and surgical site nosocomial infections of Acinetobacter baumannii and pseudomonas aeruginosa among patients hospitalized at Felegehiwot Referral Hospital, Northwest Ethiopia: a cross-sectional study. BMC Infect Dis. 2020;20(1):92. doi:10.1186/s12879-020-4811-8

36. Ruppé É, Woerther PL, Barbier F. Mechanisms of antimicrobial resistance in gram-negative bacilli. Ann Intensive Care. 2015;5 (1):61. doi:10.1186/s13613-015-0061-0

37. Walsh CT, Wencewicz TA. Prospects for new antibiotics: a molecule-centered perspective. J Antibiot (Tokyo). 2014;67 (1):7-22. doi:10.1038/ja.2013.49

38. Shirley M. Ceftazidime-avibactam: a review in the treatment of serious gram-negative bacterial infections. Drugs. 2018;78 (6):675-692. doi:10.1007/s40265-018-0902-x

39. Sharma R, Park TE, Moy S. Ceftazidime-avibactam: a novel cephalosporin/B-lactamase inhibitor combination for the treatment of resistant gram-negative organisms. Clin Ther. 2016;38 (3):431-444. doi:10.1016/j.clinthera.2016.01.018

40. Avycaz FDA highlights of prescribing information. Available from: https://www.accessdata.fda.gov/drugsatfda_docs/label/ 2017/206494s003lbl.pdf. Accessed March 29, 2018.

41. Carmeli Y, Armstrong J, Laud PJ, et al. Ceftazidime-avibactam or best available therapy in patients with ceftazidime-resistant Enterobacteriaceae and pseudomonas aeruginosa complicated urinary tract infections or complicated intra-abdominal infections (reprise): a randomised, pathogen-directed, phase 3 study. Lancet Infect Dis. 2016;16(6):661-673. doi:10.1016/S1473-3099(16) 30004-4 
42. Mazuski JE, Gasink LB, Armstrong J, et al. Efficacy and safety of ceftazidime-avibactam plus metronidazole versus meropenem in the treatment of complicated intra-abdominal infection: results from a randomized, controlled, double-blind, phase 3 program. Clin Infect Dis. 2016;62(11):1380-1389. doi:10.1093/cid/ciw133

43. Wang Y, Wang J, Wang R, Cai Y. Resistance to ceftazidime-avibactam and underlying mechanisms. J Glob Antimicrob Resist. 2020;22:18-27. doi:10.1016/j.jgar.2019.12.009

44. Raj G, Priyadarshini R, Murugesan S, Adhimoolam M. Monoclonal antibodies against infectious microbes: so long and too little! infect disord drug targets. Infect Disord Drug Targets. 2020;21(1):4-27.

45. Henning LN, Carpenter S, Stark GV, Serbina NV. Development of protective immunity in New Zealand white rabbits challenged with bacillus anthracis spores and treated with antibiotics and obiltoxaximab, a monoclonal antibody against protective antigen. Antimicrob Agents Chemother. 2018;62(2). doi:10.1128/ AAC.01590-17

46. Nagy CF, Leach TS, King A, Guttendorf R. Safety, pharmacokinetics, and immunogenicity of obiltoxaximab after intramuscular administration to healthy humans. Clin Pharmacol Drug Dev. 2018;7(6):652-660. doi:10.1002/cpdd.410

47. Deeks ED. Bezlotoxumab: a review in preventing clostridium difficile infection recurrence. Drugs. 2017;77(15):1657-1663. doi:10.1007/s40265-017-0809-y

48. Johnson S, Gerding DN. Bezlotoxumab. Clin Infect Dis. 2019;68 (4):699-704. doi:10.1093/cid/ciy577

49. Shiu J, Ting G, Kiang TK. Clinical pharmacokinetics and pharmacodynamics of delafloxacin. Eur J Drug Metab Pharmacokinet. 2019;44 (3):305-317. doi:10.1007/s13318-018-0520-8

50. Bassetti M, Pecori D, Cojutti P, Righi E, Pea F. Clinical and pharmacokinetic drug evaluation of delafloxacin for the treatment of acute bacterial skin and skin structure infections. Expert Opin Drug Metab Toxicol. 2017;13(11):1193-1200. doi:10.1080/ 17425255.2017.1386654

51. Markham A. Delafloxacin: first global approval. Drugs. 2017;77 (13):1481-1486. doi:10.1007/s40265-017-0790-5

52. Cho JC, Zmarlicka MT, Shaeer KM, Pardo J. Meropenem/vaborbactam, the first carbapenem/ $\beta$-lactamase inhibitor combination. Ann Pharmacother. 2018;52(8):769-779. doi:10.1177/ 1060028018763288

53. Lomovskaya O, Sun D, Rubio-Aparicio D, et al. Vaborbactam: spectrum of beta-lactamase inhibition and impact of resistance mechanisms on activity in Enterobacteriaceae. Antimicrob Agents Chemother. 2017;61(11). doi:10.1128/AAC.01443-17

54. Zhanel GG, Lawrence $\mathrm{CK}$, Adam H, et al. Imipenem-relebactam and meropenem-vaborbactam: two novel carbapenem-Blactamase inhibitor combinations. Drugs. 2018;78(1):65-98. doi:10.1007/s40265-017-0851-9

55. Dhillon S. Meropenem/vaborbactam: a review in complicated urinary tract infections. Drugs. 2018;78(12):1259-1270. doi:10.1007/s40265-018-0966-7

56. Ozenoxacin. FDA highlights of prescribing information. Available from: https:/www.accessdata.fda.gov/drugsatfda_docs/ label/2017/208945lbl.pdf. Accessed March 24, 2018.

57. Pascale R, Giannella M, Bartoletti M, Viale P, Pea F. Use of meropenem in treating carbapenem-resistant Enterobacteriaceae infections. Expert Rev Anti Infect Ther. 2019;17(10):819-827. doi:10.1080/14787210.2019.1673731

58. Saravolatz LD, Stein GE. Plazomicin: a new aminoglycoside. Clin Infect Dis. 2020;70(4):704-709. doi:10.1093/cid/ciz640

59. Zemdri (Plazomicin) FDA highlights of prescribing information. Available from: https:/www.accessdata.fda.gov/drugsatfda_docs/ label/2018/210303Orig1s000lbl.pdf. Accessed November 27, 2021.

60. Hussar DA. New drugs 2019, part 4. Nursing. 2019;49 (11):34-43. doi:10.1097/01.NURSE.0000585892.82614.f4
61. Eljaaly K, Alharbi A, Alshehri S, Ortwine JK, Pogue JM. Plazomicin: a novel aminoglycoside for the treatment of resistant gram-negative bacterial infections. Drugs. 2019;79(3):243-269. doi:10.1007/s40265-019-1054-3

62. Zhanel GG, Cheung D, Adam H, et al. Review of eravacycline, a novel fluorocycline antibacterial agent. Drugs. 2016;76 (5):567-588. doi:10.1007/s40265-016-0545-8

63. Scott LJ. Eravacycline: a review in complicated intra-abdominal infections. Drugs. 2019;79(3):315-324. doi:10.1007/s40265-019 01067-3

64. Heaney M, Mahoney MV, Gallagher JC. Eravacycline: the tetracyclines strike back. Ann Pharmacother. 2019;53(11):1124-1135. doi:10.1177/1060028019850173

65. Lee YR, Burton CE. Eravacycline, a newly approved fluorocycline. Eur J Clin Microbiol Infect Dis. 2019;38 (10):1787-1794. doi:10.1007/s10096-019-03590-3

66. Moore AY, Del Rosso J, Johnson JL, Grada A. Sarecycline: a review of preclinical and clinical evidence. Clin Cosmet Investig Dermatol. 2020;13:553-560. doi:10.2147/CCID.S190473

67. Moore AY, Charles JEM, Moore S. Sarecycline: a narrow spectrum tetracycline for the treatment of moderate-to-severe acne vulgaris. Future Microbiol. 2019;14(14):1235-1242. doi:10.2217/fmb-20190199

68. Haidari W, Bruinsma R, Cardenas-de la Garza JA, Feldman SR. Sarecycline review. Ann Pharmacother. 2020;54(2):164-170. doi:10.1177/1060028019873111

69. Rodvold KA, Burgos RM, Tan X, Pai MP. Omadacycline: a review of the clinical pharmacokinetics and pharmacodynamics. Clin Pharmacokinet. 2020;59(4):409-425. doi:10.1007/s40262-01900843-4

70. Gallagher JC. Omadacycline: a modernized tetracycline. Clin Infect Dis. 2019;69(Suppl 1):S1-s5. doi:10.1093/cid/ciz 394

71. Zhanel GG, Esquivel J, Zelenitsky S, et al. Omadacycline: a novel oral and intravenous aminomethylcycline antibiotic agent. Drugs. 2020;80(3):285-313. doi:10.1007/s40265-020-01257-4

72. Riddle MS, Connor P, Tribble DR. Antibiotics for travellers' diarrhoea on trial-is there a potential role for rifamycin SV? J Travel Med. 2019;26(1). doi:10.1093/jtm/tay137

73. US Food \& Drug Administration; 2018. FDA approves new drug to treat travelers' diarrhea. Available from: https://www.fda.gov/ NewsEvents/Newsroom/PressAnnouncements/ucm626121.htm. Accessed November 16, 2018.

74. Hoy SM. Rifamycin SV MMX $\left({ }^{\circledR}\right)$ : a review in the treatment of traveller's diarrhoea. Clin Drug Investig. 2019;39(7):691-697. doi:10.1007/s40261-019-00808-2

75. Ghazi IM, El Nekidy WS, Asay R, Fimognari P, Knarr A, Awad M. Simultaneous administration of imipenem/cilastatin/ relebactam with selected intravenous antimicrobials, a stewardship approach. PLoS One. 2020;15(5):e0233335. doi:10.1371/journal.pone.0233335

76. Thakare R, Dasgupta A, Chopra S. Imipenem/cilastatin sodium/ relebactam fixed combination to treat urinary infections and complicated intra-abdominal bacterial infections. Drugs Today (Barc). 2020;56(4):241-255. doi:10.1358/dot.2020.56.4.3075 796

77. Lucasti C, Vasile L, Sandesc D, et al. Phase 2, dose-ranging study of relebactam with imipenem-cilastatin in subjects with complicated intra-abdominal infection. Antimicrob Agents Chemother. 2016;60(10):6234-6243. doi:10.1128/AAC.00633-16

78. Singh R, Manjunatha U, Boshoff HI, et al. Pa-824 kills nonreplicating mycobacterium tuberculosis by intracellular no release. Science. 2008;322(5906):1392-1395. doi:10.1126/science. 1164571

79. Pretomanid tablets: us prescribing information. Available from: https://www.fda.gov/. Accessed August 27, 2019. 
80. Conradie A, Everitt D, Mendel C, et al. Sustained high rate of successful treatment outcomes: interim results of 75 patients in the Nix-TB clinical study of pretomanid, bedaquiline and linezolid [Abstract No. Oa03-213-25 and presentation]. Int J Tuberc Lung Dis. 2018;22 (Suppl.2):S69.

81. Keam SJ. Pretomanid: first approval. Drugs. 2019;79 (16): 1797-1803. doi:10.1007/s40265-019-01207-9

82. El-Lababidi RM, Rizk JG. Cefiderocol: a siderophore cephalosporin. Ann Pharmacother. 2020;54(12):1215-1231. doi:10.1177/1060028020929988

83. FDA Fetroja (Cefiderocol) for injection, for intravenous use. Available from: https://www.accessdata.fda.gov/drugsatfda_docs/ label/2019/209445s000lbl.pdf. Accessed November 14, 2019.

84. Zhanel GG, Golden AR, Zelenitsky S, et al. Cefiderocol: a siderophore cephalosporin with activity against carbapenem-resistant and multidrug-resistant gram-negative bacilli. Drugs. 2019;79(3):271-289. doi:10.1007/s40265-019$1055-2$

85. Choi JJ, McCarthy MW. Cefiderocol: a novel siderophore cephalosporin. Expert Opin Investig Drugs. 2018;27 (2):193-197. doi:10.1080/13543784.2018.1426745

86. Tang HJ, Wang JH, Lai CC. Lefamulin vs moxifloxacin for community-acquired bacterial pneumonia. Medicine (Baltimore). 2020;99(29):e21223. doi:10.1097/MD.0000000000021223

87. Veve MP, Wagner JL. Lefamulin: review of a promising novel pleuromutilin antibiotic. Pharmacotherapy. 2018;38(9):935-946. doi:10.1002/phar.2166

88. Zhanel GG, Deng C, Zelenitsky S, et al. Lefamulin: A Novel Oral and Intravenous Pleuromutilin for the Treatment of CommunityAcquired Bacterial Pneumonia. Drugs. 2021;81(2):233-256. doi:10.1007/s40265-020-01443-4

89. Koulenti D, Song A, Ellingboe A, et al. Infections by multidrugresistant gram-negative bacteria: what's new in our arsenal and what's in the pipeline? Int $J$ Antimicrob Agents. 2019;53 (3):211-224. doi:10.1016/j.ijantimicag.2018.10.011

90. Livermore DM, Mushtaq S, Meunier D, et al. Activity of ceftolozane/tazobactam against surveillance and 'problem' Enterobacteriaceae, pseudomonas aeruginosa and non-fermenters from the British Isles. J Antimicrob Chemother. 2017;72 (8):2278-2289. doi:10.1093/jac/dkx136

91. Seifert H, Körber-Irrgang B, Kresken M. In-vitro activity of ceftolozane/tazobactam against Pseudomonas aeruginosa and Enterobacteriaceae isolates recovered from hospitalized patients in Germany. Int $J$ Antimicrob Agents. 2018;51(2):227-234. doi:10.1016/j.ijantimicag.2017.06.024

92. Cluck D, Lewis P, Stayer B, Spivey J, Moorman J. Ceftolozanetazobactam: a new-generation cephalosporin. Am J Health Syst Pharm. 2015;72(24):2135-2146. doi:10.2146/ajhp150049

93. Pfaller MA, Shortridge D, Sader HS, Castanheira M, Flamm RK. Ceftolozane/tazobactam activity against drug-resistant Enterobacteriaceae and pseudomonas aeruginosa causing healthcare-associated infections in the Asia-Pacific region (Minus China, Australia and New Zealand): report from an Antimicrobial Surveillance Programme (2013-2015). Int J Antimicrob Agents. 2018;51(2):181-189. doi:10.1016/j.ijantimicag.2017.09.016

94. Livermore DM, Meunier D, Hopkins KL, et al. Activity of ceftazidime/avibactam against problem Enterobacteriaceae and Pseudomonas aeruginosa in the UK, 2015-16. J Antimicrob Chemother. 2018;73(3):648-657. doi:10.1093/jac/dkx438

95. Bassetti M, Labate L, Vena A, Giacobbe DR. Role or oritavancin and dalbavancin in acute bacterial skin and skin structure infections and other potential indications. Curr Opin Infect Dis. 2021;34(2):96-108. doi:10.1097/QCO.0000000000 000714
96. Wang Y, Wang J, Wang R, Li Y, Cai Y. Efficacy and safety of dalbavancin in the treatment of gram-positive bacterial infections. $J$ Glob Antimicrob Resist. 2020;24:72-80. doi:10.1016/j.jgar.20 20.11.018

97. Bongiorno D, Lazzaro LM, Stefani S, Campanile F. In vitro activity of dalbavancin against refractory multidrug-resistant (MDR) Staphylococcus aureus isolates. Antibiotics (Basel). 2020;9(12). doi:10.3390/antibiotics9120865

98. Zahornacký O, Novotný M. [Dalbavancin and its use in the treatment of methicillin-resistant Staphylococcus aureus - induced upper limb phlegmon]. Klin Mikrobiol Infekc Lek. 2020;26 (2):51-53. Slovak.

99. Meyer J, Lata P, Barnett S. Continued dosing of oritavancin for complicated gram-positive infections. Fed Pract. 2020;37 (11):502-504. doi:10.12788/fp.0068

100. Dretske D, Schulz L, Werner E, Sharp B, Pulia M. Effectiveness of oritavancin for management of skin and soft tissue infections in the emergency department: a case series. Am J Emerg Med. 2021;43:77-80. doi:10.1016/j.ajem.2021.01.050

101. US Food \& Drug Administration; 2021. Antimicrobial resistance information from FDA. Available from: https://www.fda.gov/ emergency-preparedness-and-response/mcm-issues/antimicrobialresistance-information-fda\#top. Accessed November 24, 2021.

102. Brownell LE, Adamsick ML, McCreary EK, et al. Clinical outcomes and economic impact of oritavancin for gram-positive infections: a single academic medical center health system experience. Drugs Real World Outcomes. 2020;7(Supp1 1):13-19. doi:10.1007/s40801-020-00192-w

103. Melinta Therapeutics LLC; 2021.Kimyrsa ${ }^{\mathrm{TM}}$ (Oritavancin) for injection [Prescribing information]. Available from: https://melin tamedicalinformation.com/Media/PI/KIMYRSA\%20Prescribing \%20Information\%2007\%202021.pdf. Accessed July 29, 2018.

104. Loza E, Sarciaux M, Ikaunieks M, et al. Structure-activity relationship studies on the inhibition of the bacterial translation of novel odilorhabdins analogues. Bioorg Med Chem. 2020;28 (11):115469. doi:10.1016/j.bmc.2020.115469

105. Racine E, Gualtieri M. From worms to drug candidate: the story of odilorhabdins, a new class of antimicrobial agents. Front Microbiol. 2019;10:2893. doi:10.3389/fmicb.2019.02893

106. Pantel L, Florin T, Dobosz-Bartoszek M, et al. Odilorhabdins, antibacterial agents that cause miscoding by binding at a new ribosomal site. Mol Cell. 2018;70(1):83-94.e87. doi:10.1016/j. molcel.2018.03.001

107. Breijyeh Z, Jubeh B, Karaman R. Resistance of gram-negative bacteria to current antibacterial agents and approaches to resolve it. Molecules. 2020;25(6):1340. doi:10.3390/molecules25061340

108. Jin K, Po KHL, Wang S, et al. Synthesis and structure-activity relationship of teixobactin analogues via convergent Ser Ligation. Bioorg Med Chem. 2017;25(18):4990-4995. doi:10.1016/j. bmc.2017.04.039

109. Guo C, Mandalapu D, Ji X, Gao J, Zhang Q. Chemistry and biology of teixobactin. Chemistry. 2018;24(21):5406-5422. doi:10.1002/chem.201704167

110. Liu Y, Liu Y, Chan-Park MB, Mu Y. Binding modes of teixobactin to lipid II: molecular dynamics study. Sci Rep. 2017;7 (1):17197. doi:10.1038/s41598-017-17606-5

111. Ling LL, Schneider T, Peoples AJ, et al. A new antibiotic kills pathogens without detectable resistance. Nature. 2015;517 (7535):455-459. doi:10.1038/nature14098

112. Huanyun Z, Ruijuan L. Research progress of a new antibiotic teixobactin that is not easy to induce resistance. Chin J Antibiot. 2019;44(01):9-17.

113. Jin K, Sam IH, Po KHL, et al. Total synthesis of teixobactin. Nat Commun. 2016;7:12394. doi:10.1038/ncomms12394 
114. Giltrap AM, Dowman LJ, Nagalingam G, et al. Total synthesis of teixobactin. Org Lett. 2016;18(11):2788-2791. doi:10.1021/acs. orglett.6b01324

115. Parmar A, Lakshminarayanan R, Iyer A, et al. Design and syntheses of highly potent teixobactin analogues against Staphylococcus aureus, methicillin-resistant Staphylococcus aureus (MRSA), and vancomycin-resistant enterococci (VRE) in vitro and in vivo. $J$ Med Chem. 2018;61(5):2009-2017. doi:10.1021/acs.jmedchem.7b01634

116. Liu J, Smith PA, Steed DB, Romesberg F. Efforts toward broadening the spectrum of arylomycin antibiotic activity. Bioorg Med Chem Lett. 2013;23(20):5654-5659. doi:10.1016/j.bmcl.2013.08.026

117. Smith PA, Koehler MFT, Girgis HS, et al. Optimized arylomycins are a new class of gram-negative antibiotics. Nature. 2018;561 (7722):189-194. doi:10.1038/s41586-018-0483-6

118. Lam YC, Crawford JM. Discovering antibiotics from the global microbiome. Nat Microbiol. 2018;3(4):392-393. doi:10.1038/ s41564-018-0135-5

119. Kleijn LH, Oppedijk SF, Hart P, et al. Total synthesis of laspartomycin $\mathrm{C}$ and characterization of its antibacterial mechanism of action. J Med Chem. 2016;59(7):3569-3574. doi:10.1021/acs. jmedchem.6b00219

120. Hover BM, Kim SH, Katz M, et al. Culture-independent discovery of the malacidins as calcium-dependent antibiotics with activity against multidrug-resistant gram-positive pathogens. Nat Microbiol. 2018;3(4):415-422. doi:10.1038/s41564-018-0110-1

121. Hart EM, Mitchell AM, Konovalova A, et al. A small-molecule inhibitor of bama impervious to efflux and the outer membrane permeability barrier. Proc Natl Acad Sci U S A. 2019;116 (43):21748-21757. doi:10.1073/pnas.1912345116

122. Imai $\mathrm{Y}$, Meyer KJ, Iinishi A, et al. A new antibiotic selectively kills gram-negative pathogens. Nature. 2019;576(7787):459-464. doi:10.1038/s41586-019-1791-1

123. Stokes JM, Yang K, Swanson K, et al. A deep learning approach to antibiotic discovery. Cell. 2020;180(4):688-702.e613. doi:10.1016/j.cell.2020.01.021

124. Stokes JM, Gutierrez A, Lopatkin AJ, et al. A multiplexable assay for screening antibiotic lethality against drug-tolerant bacteria. Nat Methods. 2019;16(4):303-306. doi:10.1038/s41592-019-0333-y

125. Balaban NQ, Helaine S, Lewis K, et al. Definitions and guidelines for research on antibiotic persistence. Nat Rev Microbiol. 2019;17 (7):441-448. doi:10.1038/s41579-019-0196-3

126. Böhringer N, Patras MA, Schäberle TF. Heterologous expression of pseudouridimycin and description of the corresponding minimal biosynthetic gene cluster. Molecules. 2021;26(2):510. doi:10.3390/molecules26020510

127. Chellat MF, Riedl R. Pseudouridimycin: the first nucleoside analogue that selectively inhibits bacterial RNA polymerase. Angew Chem Int Ed Engl. 2017;56(43):13184-13186. doi:10.1002/ anie. 201708133

128. O'Malley PA. Pseudouridimycin: light in the darkness of antimicrobial resistance. Clin Nurse Spec. 2018;32(3):114-115. doi:10.1097/NUR.0000000000000367

129. Maffioli SI, Zhang Y, Degen D, et al. Antibacterial nucleoside-analog inhibitor of bacterial RNA polymerase. Cell. 2017;169(7):1240-1248.e1223. doi:10.1016/j.cell.2017.05.042

130. Krasavin M, Trifonov RE, Tolstyakov VV, et al. 5-methyl-7-(3-Nitro[1,2,4]Triazol-1-Y1)-[1,2,4]Triazolo[1,5-a]Pyrimidine, having anti-tuberculosis activity against the agent with multiple drug resistance, and a method for production thereof. Chem. 2019;171:563769.

131. Chuprun S, Dar'in D, Rogacheva E, et al. Mutually isomeric 2and 4-(3-Nitro-1,2,4-Triazol-1-Y1)pyrimidines inspired by an antimycobacterial screening hit: synthesis and biological activity against the eskape panel of pathogens. Antibiotics (Basel). 2020;9 (10). doi:10.3390/antibiotics9100666
132. Deming Z, Taiping H, Sanqi Z, Ningren J. Synthesis process optimization of methoxycephalosporin intermediate 7-amca. Guangzhou Chem Indust. 2009;37(09):80-83.

133. Yan R, Ning J, Yuan W. (6s) or (7s)-methoxy B-lactam antibiotics. Foreign Med. 2007;6:252-258+276.

134. Shaohua L, Wei W, Zengying H, Hongming L, Shenghua C, Xiaodong D. Improvement of synthesis process of methoxef intermediate 7-MAC. Chem Res Appl. 2013;25(04):547-549.

135. Kuailin S, Runsun L, Xinghan L. Studies on B-lactam antibioticsII. Synthesis of 7-substituted azide cephalosporins and $7 \alpha$-methoxy $-7 \beta$ substituted hydrazone cephalosporins. Antibiotics. 1985;3:165-166.

136. Lili T, Li W, Jiaxin L, Dacheng W, Feng G, Lin W. Evaluation of the antibacterial activity of a new cephalosporin compound NAC-3 and its in vivo protection against MRSA infections. Chin J Vet Med. 2020;40(08):1571-1578.

137. Serafim MSM, Lavorato SN, Kronenberger T, et al. Antibacterial activity of synthetic 1,3-Bis(Aryloxy)propan-2-amines against gram-positive bacteria. Microbiologyopen. 2019;8(11):e814. doi: $10.1002 / \mathrm{mbo} 3.814$

138. Barman S, Konai MM, Samaddar S, Haldar J. Amino acid conjugated polymers: antibacterial agents effective against drug-resistant Acinetobacter baumannii with no detectable resistance. ACS Appl Mater Interfaces. 2019;11(37):3355 9-33572. doi:10.1021/acsami.9b09016

139. Mukherjee I, Ghosh A, Bhadury P, De P. Side-chain amino acid-based cationic antibacterial polymers: investigating the morphological switching of a polymer-treated bacterial cell. ACS Omega. 2017;2(4):1633-1644. doi:10.1021/acsomega.7b00181

140. Jean SS, Gould IM, Lee WS, Hsueh PR. New drugs for multidrug-resistant gram-negative organisms: time for stewardship. Drugs. 2019;79(7):705-714. doi:10.1007/s40265-019-01112-1

141. Hamrick JC, Docquier JD, Uehara T, et al. Vnrx-5133 (Taniborbactam), a broad-spectrum inhibitor of serine- and metallo-B-lactamases, restores activity of cefepime in enterobacterales and Pseudomonas aeruginosa. Antimicrob Agents Chemother. 2020;64(3). doi:10.1128/AAC.01963-19

142. Wang X, Zhao C, Wang Q, et al. In vitro activity of the novel Blactamase inhibitor taniborbactam (Vnrx-5133), in combination with cefepime or meropenem, against MDR gram-negative bacterial isolates from China. J Antimicrob Chemother. 2020;75 (7):1850-1858. doi:10.1093/jac/dkaa053

143. Thwaites M, Hall D, Stoneburner A, et al. Activity of plazomicin in combination with other antibiotics against multidrug-resistant Enterobacteriaceae. Diagn Microbiol Infect Dis. 2018;92 (4):338-345. doi:10.1016/j.diagmicrobio.2018.07.006

144. Procópio TF, Moura MC, Bento EFL, et al. Looking for alternative treatments for bovine and caprine mastitis: evaluation of the potential of Calliandra surinamensis leaf pinnulae lectin (Casul), both alone and in combination with antibiotics. Microbiologyopen. 2019;8(11):e869. doi:10.1002/mbo3.869

145. Breidenstein EB, de la Fuente-núñez $C$, Hancock RE. Pseudomonas aeruginosa: all roads lead to resistance. Trends Microbiol. 2011;19(8):419-426. doi:10.1016/j.tim.2011.04.005

146. Yang X, Goswami S, Gorityala BK, et al. A tobramycin vector enhances synergy and efficacy of efflux pump inhibitors against multidrug-resistant gram-negative bacteria. J Med Chem. 2017;60 (9):3913-3932. doi:10.1021/acs.jmedchem.7b00156

147. Kalan L, Wright GD. Antibiotic adjuvants: multicomponent anti-infective strategies. Expert Rev Mol Med. 2011;13:e5. doi:10.1017/S1462399410001766

148. Brown D. Antibiotic resistance breakers: can repurposed drugs fill the antibiotic discovery void? Nat Rev Drug Discov. 2015;14 (12):821-832. doi:10.1038/nrd4675 
149. Gill EE, Franco OL, Hancock RE. Antibiotic adjuvants: diverse strategies for controlling drug-resistant pathogens. Chem Biol Drug Des. 2015;85(1):56-78. doi:10.1111/cbdd.12478

150. Butler MS, Blaskovich MA, Cooper MA. Antibiotics in the clinical pipeline in 2013. $J$ Antibiot (Tokyo). 2013;66 (10):571-591. doi:10.1038/ja.2013.86

151. Bagińska N, Pichlak A, Górski A, Jończyk-Matysiak E. Specific and selective bacteriophages in the fight against multidrug-resistant Acinetobacter baumannii. Virol Sin. 2019;34 (4):347-357. doi:10.1007/s12250-019-00125-0

152. Gordillo Altamirano F, Forsyth JH, Patwa R, et al. Bacteriophageresistant Acinetobacter baumannii are resensitized to antimicrobials. Nat Microbiol. 2021;6(2):157-161. doi:10.1038/s41564-020-00830-7

153. Souli M, Galani I, Boukovalas S, et al. In vitro interactions of antimicrobial combinations with fosfomycin against KPC-2-producing Klebsiella pneumoniae and protection of resistance development. Antimicrob Agents Chemother. 2011;55 (5):2395-2397. doi:10.1128/AAC.01086-10

154. Williams PC. Potential of fosfomycin in treating multidrug-resistant infections in children. $J$ Paediatr Child Health. 2020;56(6):864-872. doi:10.1111/jpc.14883

155. Theuretzbacher U, Van Bambeke F, Cantón R, et al. Reviving old antibiotics. J Antimicrob Chemother. 2015;70(8):2177-2181. doi:10.1093/jac/dkv157

156. Rigatto MH, Falci DR, Zavascki AP. Clinical use of polymyxin B. Adv Exp Med Biol. 2019;1145:197-218.

157. Garg SK, Singh O, Juneja D, et al. Resurgence of polymyxin B for MDR/XDR gram-negative infections: an overview of current evidence. Crit Care Res Pract. 2017;2017:3635609. doi:10.1155/2017/3635609

158. Hortle E, Johnson KE, Johansen MD, et al. Thrombocyte inhibition restores protective immunity to mycobacterial infection in zebrafish. J Infect Dis. 2019;220(3):524-534. doi:10.1093/infdis/jiz110

159. Pribis JP, García-Villada L, Zhai Y, et al. Gamblers: an antibiotic-induced evolvable cell subpopulation differentiated by reactive-oxygen-induced general stress response. Mol Cell. 2019;74(4):785-800.e787. doi:10.1016/j.molcel.2019.02.037

160. Guachalla LM, Stojkovic K, Hartl K, et al. Discovery of monoclonal antibodies cross-reactive to novel subserotypes of $\mathrm{K}$. Pneumoniae O3 Sci Rep. 2017;7(1):6635. doi:10.1038/s41598017-06682-2

161. Rollenske T, Szijarto V, Lukasiewicz J, et al. Cross-specificity of protective human antibodies against Klebsiella pneumoniae LPS O-antigen. Nat Immunol. 2018;19(6):617-624. doi:10.1038/ s41590-018-0106-2

162. Förster B, Chung PK, Crobach MJT, Kuijper EJ. Application of antibody-mediated therapy for treatment and prevention of clostridium difficile infection. Front Microbiol. 2018;9:1382. doi:10.3389/fmicb.2018.01382

163. Helbig ET, Opitz B, Sander LE. Adjuvant immunotherapies as a novel approach to bacterial infections. Immunotherapy. 2013;5 (4):365-381. doi:10.2217/imt.13.17

164. Akbari R, Hakemi Vala M, Hashemi A, Aghazadeh H, Sabatier JM, Pooshang Bagheri K. Action mechanism of melittin-derived antimicrobial peptides, MDP1 and MDP2, de novo designed against multidrug resistant bacteria. Amino Acids. 2018;50(9):1231-1243. doi:10.1007/s00726-018-2596-5

165. Di YP, Lin Q, Chen C, Montelaro RC, Doi Y, Deslouches B. Enhanced therapeutic index of an antimicrobial peptide in mice by increasing safety and activity against multidrug-resistant bacteria. Sci Adv. 2020;6(18):eaay6817. doi:10.1126/sciadv. aay6817

166. Khara JS, Obuobi S, Wang Y, et al. Disruption of drug-resistant biofilms using de novo designed short A-helical antimicrobial peptides with idealized facial amphiphilicity. Acta Biomater. 2017;57:103-114. doi:10.1016/j.actbio.2017.04.032
167. Li SA, Lee WH, Zhang Y. Efficacy of OH-CATH30 and its analogs against drug-resistant bacteria in vitro and in mouse models. Antimicrob Agents Chemother. 2012;56(6):3309-3317. doi:10.1128/AAC.06304-11

168. Zhao F, Lan XQ, Du Y, et al. King cobra peptide OH-CATH30 as a potential candidate drug through clinic drug-resistant isolates. Zool Res. 2018;39(2):87-96. doi:10.24272/j.issn.2095-8137.2018.025

169. Sun H, Wei C, Liu B, et al. Induction of systemic and mucosal immunity against methicillin-resistant Staphylococcus aureus infection by a novel nanoemulsion adjuvant vaccine. Int J Nanomedicine. 2015;10:7275-7290. doi:10.2147/IJN.S91529

170. Pierpaoli E, Orlando F, Cirioni O, Simonetti O, Giacometti A, Provinciali M. Supplementation with tocotrienols from bixa orellana improves the in vivo efficacy of daptomycin against methicillin-resistant Staphylococcus aureus in a mouse model of infected wound. Phytomedicine. 2017;36:50-53. doi:10.1016/j. phymed.2017.09.011

171. Mayaud L, Carricajo A, Zhiri A, Aubert G. Comparison of bacteriostatic and bactericidal activity of 13 essential oils against strains with varying sensitivity to antibiotics. Lett Appl Microbiol. 2008;47(3):167-173. doi:10.1111/j.1472-765X.2008.02406.x

172. Brehm-Stecher BF, Johnson EA. Sensitization of Staphylococcus aureus and Escherichia coli to antibiotics by the sesquiterpenoids nerolidol, farnesol, bisabolol, and apritone. Antimicrob Agents Chemother. 2003;47(10):3357-3360. doi:10.1128/AAC.47.10.33573360.2003

173. Swamy MK, Akhtar MS, Sinniah UR. Antimicrobial properties of plant essential oils against human pathogens and their mode of action: an updated review. Evid Based Complement Alternat Med. 2016;2016:3012462. doi:10.1155/2016/3012462

174. Süntar I, Akkol EK, Keleş H, et al. Healing ointment: a formulation of hypericum perforatum oil and sage and oregano essential oils based on traditional Turkish knowledge. J Ethnopharmacol. 2011;134 (1):89-96. doi:10.1016/j.jep.2010.11.061

175. Zhou Y, Xie M, Song Y, et al. Two traditional Chinese medicines curcumae radix and curcumae rhizoma: an ethnopharmacology, phytochemistry, and pharmacology review. Evid Based Complement Alternat Med. 2016;2016:4973128. doi:10.1155/2016/4973128

176. Tariq S, Wani S, Rasool W, et al. A comprehensive review of the antibacterial, antifungal and antiviral potential of essential oils and their chemical constituents against drug-resistant microbial pathogens. Microb Pathog. 2019;134:103580. doi:10.1016/j. micpath.2019.103580

177. Yap PS, Yiap BC, Ping HC, Lim SH. Essential oils, a new horizon in combating bacterial antibiotic resistance. Open Microbiol J. 2014;8:6-14. doi:10.2174/1874285801408010006

178. Lahmar A, Bedoui A, Mokdad-Bzeouich I, et al. Reversal of resistance in bacteria underlies synergistic effect of essential oils with conventional antibiotics. Microb Pathog. 2017;106:50-59. doi:10.1016/j.micpath.2016.10.018

179. Solórzano-Santos F, Miranda-Novales MG. Essential oils from aromatic herbs as antimicrobial agents. Curr Opin Biotechnol. 2012;23(2):136-141. doi:10.1016/j.copbio.2011.08.005

180. Yu Z, Tang J, Khare T, Kumar V. The alarming antimicrobial resistance in ESKAPEE pathogens: can essential oils come to the rescue? Fitoterapia. 2020;140:104433. doi:10.1016/j.fitote.2019.104433

181. Oliva A, Costantini S, De Angelis M, et al. High potency of melaleuca alternifolia essential oil against multi-drug resistant gram-negative bacteria and methicillin-resistant Staphylococcus aureus. Molecules. 2018;23(10):2584. doi:10.3390/molecules2 3102584

182. Marchitto MC, Dillen CA, Liu H, et al. Clonal V $\gamma 6(+) \mathrm{V} \delta 4(+)$ $\mathrm{T}$ cells promote Il-17-mediated immunity against Staphylococcus aureus skin infection. Proc Natl Acad Sci U S A. 2019;116 (22):10917-10926. doi:10.1073/pnas.1818256116 
183. Raz A, Serrano A, Lawson C, et al. Lysibodies Are Igg Fc fusions with lysin binding domains targeting Staphylococcus aureus wall carbohydrates for effective phagocytosis. Proc Natl Acad Sci $U S$ A. 2017;114(18):4781-4786. doi:10.1073/pnas.1619249114

184. Raz A, Serrano A, Thaker M, Alston T, Fischetti VA. Lysostaphin lysibody leads to effective opsonization and killing of methicillin-resistant Staphylococcus aureus in a murine model. Antimicrob Agents Chemother. 2018;62(10). doi:10.1128/ AAC.01056-18

185. Kalia VC, Wood TK, Kumar P. Evolution of resistance to quorum-sensing inhibitors. Microb Ecol. 2014;68(1):13-23. doi:10.1007/s00248-013-0316-y

186. Tonkin M, Khan S, Wani MY, Ahmad A. Quorum sensing a stratagem for conquering multi-drug resistant pathogens. Curr Pharm Des. 2020. doi:10.2174/1381612826666201210105638

187. Shaaban M, Elgaml A, Habib EE. Biotechnological applications of quorum sensing inhibition as novel therapeutic strategies for multidrug resistant pathogens. Microb Pathog. 2019;127: 138-143. doi:10.1016/j.micpath.2018.11.043

188. Kumar M, Saxena M, Saxena AK, Nandi S. Recent breakthroughs in various antimicrobial resistance induced quorum sensing biosynthetic pathway mediated targets and design of their inhibitors. Comb Chem High Throughput Screen. 2020;23(6):458-476. doi:10.2174/1386207323666200425205808

189. Hu Y, Kwan BW, Osbourne DO, Benedik MJ, Wood TK. Toxin YafQ increases persister cell formation by reducing indole signalling. Environ Microbiol. 2015;17(4):1275-1285. doi:10.11 11/1462-2920.12567

190. Wang Y, Tian T, Zhang J, et al. Indole reverses intrinsic antibiotic resistance by activating a novel dual-function importer. mBio. 2019;10(3). doi:10.1128/mBio.00676-19

191. Brix A, Cafora M, Aureli M, Pistocchi A. Animal models to translate phage therapy to human medicine. Int $J$ Mol Sci. 2020;21(10):3715. doi:10.3390/ijms21103715

192. Fischetti VA. Development of phage lysins as novel therapeutics: a historical perspective. Viruses. 2018;10(6):310. doi:10.3390/ v10060310

193. Jeon J, Park JH, Yong D. Efficacy of bacteriophage treatment against carbapenem-resistant Acinetobacter baumannii in galleria mellonella larvae and a mouse model of acute pneumonia. BMC Microbiol. 2019;19(1):70. doi:10.1186/s12866-019-1443-5

194. Karaiskos I, Galani I, Souli M, Giamarellou H. Novel B-lactam -B-lactamase inhibitor combinations: expectations for the treatment of carbapenem-resistant gram-negative pathogens. Expert Opin Drug Metab Toxicol. 2019;15(2):133-149. doi:10.1080/ 17425255.2019 .1563071
195. Giacobbe DR, Mikulska M, Viscoli C. Recent advances in the pharmacological management of infections due to multidrug-resistant gram-negative bacteria. Expert Rev Clin Pharmacol. 2018;11(12):1219-1236. doi:10.1080/17512433.20 18.1549487

196. Han JW, Choi GJ, Kim BS. Antimicrobial aromatic polyketides: a review of their antimicrobial properties and potential use in plant disease control. World J Microbiol Biotechnol. 2018;34 (11):163. doi:10.1007/s11274-018-2546-0

197. Chen J, Li X, Li L, et al. Coagulation factors Vii, Ix and X are effective antibacterial proteins against drug-resistant gram-negative bacteria. Cell Res. 2019;29(9):711-724. doi:10.1038/s41422-019-0202-3

198. Li C, You X. Coagulation factors: a novel class of endogenous host antimicrobial proteins against drug-resistant gram-negative bacteria. Signal Transduct Target Ther. 2019;4:46. doi:10.1038/ s41392-019-0083-4

199. Hegeto LA, Caleffi-Ferracioli KR, Perez de Souza J, et al. Promising antituberculosis activity of piperine combined with antimicrobials: a systematic review. Microb Drug Resist. 2019;25(1):120-126. doi:10.1089/mdr.2018.0107

200. Orenstein R, Patron RL, Seville MT. Why does clostridium difficile infection recur? $J$ Am Osteopath Assoc. 2019;119 (5):322-326. doi:10.7556/jaoa.2019.054

201. Dieltjens L, Appermans K, Lissens M, et al. Inhibiting bacterial cooperation is an evolutionarily robust anti-biofilm strategy. Nat Commun. 2020;11(1):107. doi:10.1038/s41467-019-13660-X

202. Hayhurst EJ, Kailas L, Hobbs JK, Foster SJ. Cell wall peptidoglycan architecture in bacillus subtilis. Proc Natl Acad Sci US A. 2008;105(38):14603-14608. doi:10.1073/pnas.0804138105

203. Turner RD, Ratcliffe EC, Wheeler R, Golestanian R, Hobbs JK, Foster SJ. Peptidoglycan architecture can specify division planes in Staphylococcus aureus. Nat Commun. 2010;1:26. doi:10.1038/ ncomms 1025

204. Pasquina-Lemonche L, Burns J, Turner RD, et al. The architecture of the gram-positive bacterial cell wall. Nature. 2020;582 (7811):294-297. doi:10.1038/s41586-020-2236-6

205. U.S. Department of Health and Human Services; Centers for Disease Control and Prevention. Antibiotic resistance threats in the United States; 2019. Available from: https:/www.cdc.gov/ drugresistance/pdf/threats-report/2019-ar-threats-report-508.pdf. Accessed March 2, 2021.
Infection and Drug Resistance

\section{Publish your work in this journal}

Infection and Drug Resistance is an international, peer-reviewed openaccess journal that focuses on the optimal treatment of infection (bacterial, fungal and viral) and the development and institution of preventive strategies to minimize the development and spread of resistance. The journal is specifically concerned with the epidemiology of

\section{Dovepress}

antibiotic resistance and the mechanisms of resistance development and diffusion in both hospitals and the community. The manuscript management system is completely online and includes a very quick and fair peerreview system, which is all easy to use. Visit http://www.dovepress.com/ testimonials.php to read real quotes from published authors. 